San Jose State University

SJSU ScholarWorks

Master's Theses

Master's Theses and Graduate Research

2009

\title{
Effects of prescribed burning on composition of serpentine grassland vegetation
}

Debra Thornley Welch

San Jose State University

Follow this and additional works at: https://scholarworks.sjsu.edu/etd_theses

\section{Recommended Citation}

Welch, Debra Thornley, "Effects of prescribed burning on composition of serpentine grassland vegetation" (2009). Master's Theses. 3661.

DOI: https://doi.org/10.31979/etd.nda7-5xp5

https://scholarworks.sjsu.edu/etd_theses/3661

This Thesis is brought to you for free and open access by the Master's Theses and Graduate Research at SJSU ScholarWorks. It has been accepted for inclusion in Master's Theses by an authorized administrator of SJSU ScholarWorks. For more information, please contact scholarworks@sjsu.edu. 
EFFECTS OF PRESCRIBED BURNING ON COMPOSITION OF SERPENTINE GRASSLAND VEGETATION

\author{
A Thesis \\ Presented to \\ The Faculty of the Department of Biological Sciences \\ San José State University
}

In Partial Fulfillment

of the Requirements for the Degree

Master of Science

by

Debra Thornley Welch

May 2009 
UMI Number: 1470998

\section{INFORMATION TO USERS}

The quality of this reproduction is dependent upon the quality of the copy submitted. Broken or indistinct print, colored or poor quality illustrations and photographs, print bleed-through, substandard margins, and improper alignment can adversely affect reproduction.

In the unlikely event that the author did not send a complete manuscript and there are missing pages, these will be noted. Also, if unauthorized copyright material had to be removed, a note will indicate the deletion.

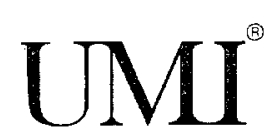

UMI Microform 1470998

Copyright 2009 by ProQuest LLC

All rights reserved. This microform edition is protected against unauthorized copying under Title 17, United States Code.

ProQuest LLC

789 East Eisenhower Parkway

P.O. Box 1346

Ann Arbor, Ml 48106-1346 
Debra Thornley Welch

ALL RIGHTS RESERVED 
SAN JOSE STATE UNIVERSITY

The Undersigned Thesis Committee Approves the Thesis Titled

EFFECTS OF PRESCRIBED BURNING ON COMPOSITION OF SERPENTINE GRASSLAND VEGETATION

by

Debra Thornley Welch

APPROVED FOR THE DEPARTMENT OF BIOLOGICAL SCIENCES
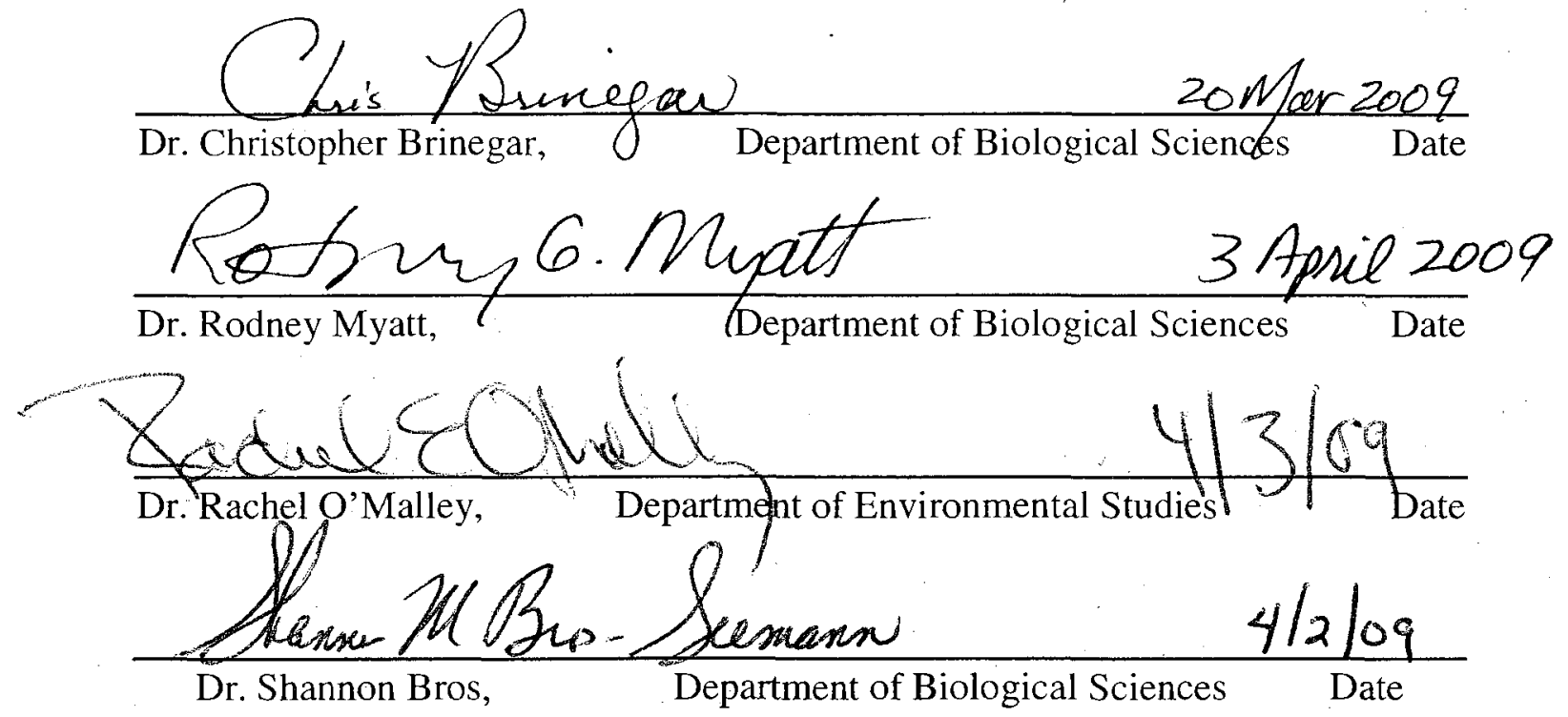

APPROVED FOR THE UNIVERSITY

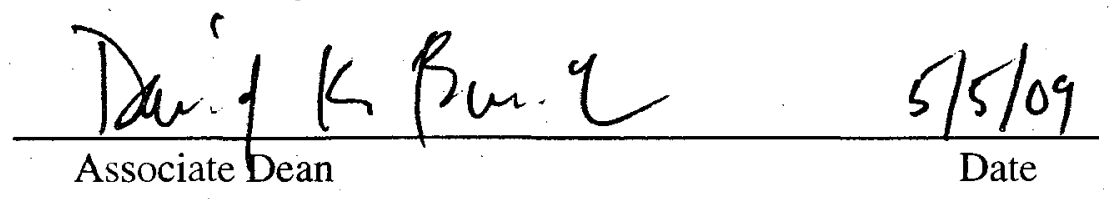




\section{ABSTRACT \\ EFFECTS OF PRESCRIBED BURNING ON COMPOSITION OF SERPENTINE GRASSLAND VEGETATION \\ by Debra Thornley Welch}

Serpentine grasslands serve as refuges for native grassland plant species. Exotic invasive plants increasingly displace even serpentine natives. Fire is a common tool used by managers to control exotic vegetation. Controlled experimental burns were conducted to evaluate the impacts of early summer burning on plant community species richness and the abundance of Leptosiphon ambiguus, Bromus hordeaceus, Lessingia micradenia var. glabrata, Plantago erecta and grasses in two kinds of patches: those with a high abundance of $L$. ambiguus and little $B$. hordeaceus, and those with a moderate abundance of both L. ambiguus and B. hordeaceus. This two-year study, conducted in Santa Clara County, California, used a Randomized Block Repeated Measure design $(n=10)$ with the treatments (burned, not burned) applied after the first year's data were collected.

From a management perspective there were three main benefits and one drawback of burning. Increases in species richness in both types of patches and the increase in $L$. ambiguus and reduction of $B$. hordeaceus in the $B$. hordeaceus-invaded patches were beneficial outcomes. The reduction of $L$. micradenia in L. ambiguus-rich patches was a drawback. Additionally, the study revealed that there was an increase in P. erecta abundance with higher burn temperatures in L. ambiguus-rich quadrats; in B. hordeaceusinvaded quadrats, there was a decrease in P. erecta abundance with higher burn temperatures. Burning also decreased the abundance of all annual grasses combined.

Overall, prescribed burning at the grazed study site appeared to be beneficial. 


\section{ACKNOWLEDGMENTS}

I am extremely grateful to the many people who helped me and were supportive of me through the process of producing my thesis. I was lucky to have such an approachable, helpful, knowledgeable committee. My committee chair, Chris Brinegar, endured wind, rain, and fire and made himself available across the country and across the world during the course of selecting, developing, performing, and writing about my experiment. Rachel O'Malley was there during the conception and development of my design. Shannon Bros-Seeman provided me with a wonderful base of statistical knowledge. Shannon and Rachel spent countless hours helping me with statistical questions and provided moral support. Rod Myatt has taught me much of what I know about plants, including plant taxonomy which was crucial to my study; my serpentine grassland plant collection provided a good foundation for identifying many plants. Rod has nurtured my love of plants in each of the classes he taught me. Each of my committee members lent special insight to my paper.

I am grateful to Santa Clara County Open Space Authority for allowing me to conduct my study at Rancho Cañada del Oro; special thanks to Pat Congdon and Derek Neumann for their help, advice, and time, and for providing the fire for this study. Thanks to Pam Peterson for putting me in touch with Pat and for brainstorming ideas with me. The wildflowers and vistas at Rancho Cañada del Oro were breathtaking.

I thank my family and friends for many kinds of support. My most-devoted data collecting buddy was Bob Roth, who even recruited his family to help. Several friends helped me with data collection and confirmed plant identifications. Many friends and 
family members provided moral support and encouragement. I am grateful to my stepdaughter, Brie, for enduring years in a home with only one income.

I dedicate my thesis to Jerry, my husband. Thank you, Jerry, for your emotional, technical, photographic, editorial and, not least of all, financial support, and for your patience during this challenge. 


\section{TABLE OF CONTENTS}

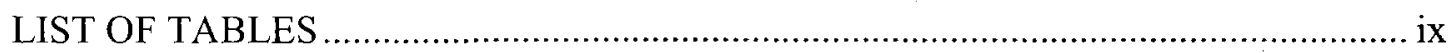

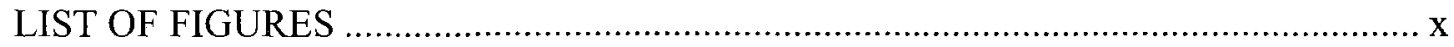

INTRODUCTION

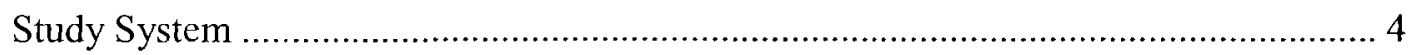

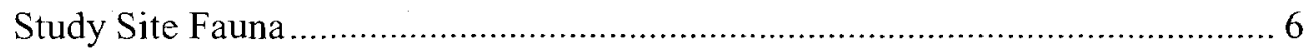

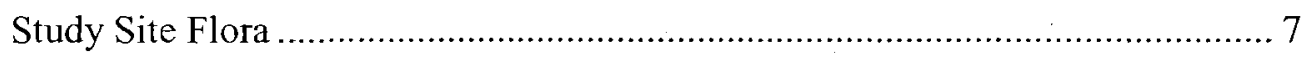

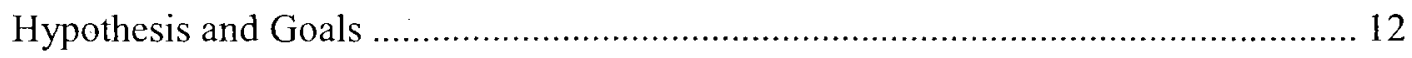

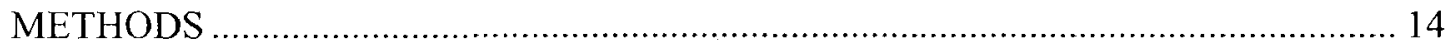

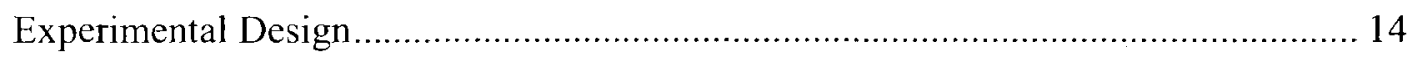

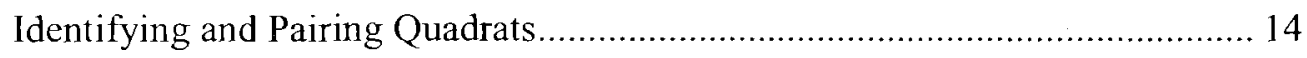

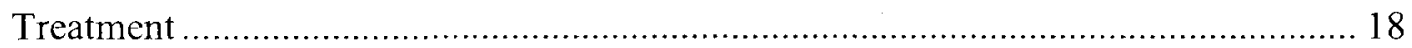

Summary of Burn Protocol and Description of Burn Boxes.............................. 18

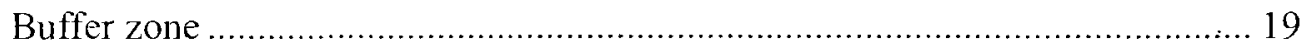

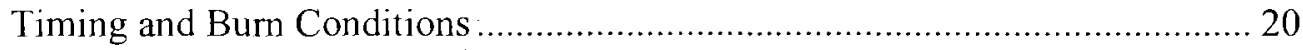

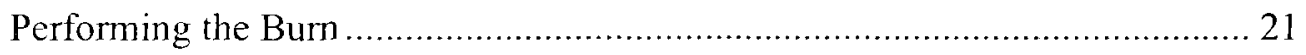

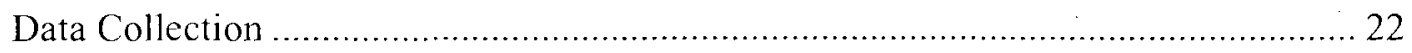

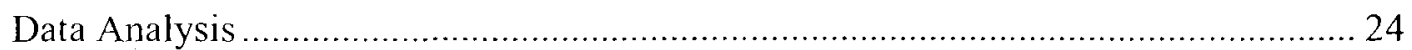

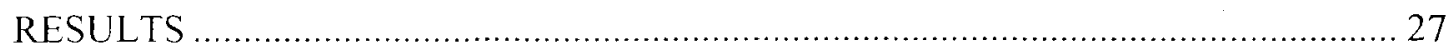

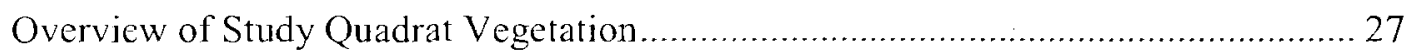

Preliminary Analyses: Initial and Disturbance Parameters ………............................ 27

Effects of Burning on L. ambiguus and B. hordeaceus Quadrats .............................. 29 


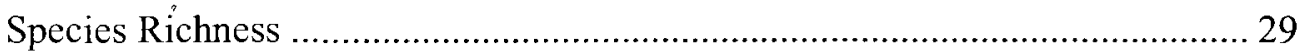

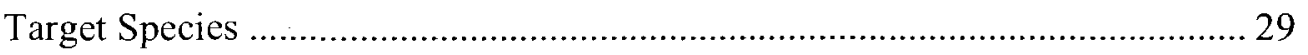

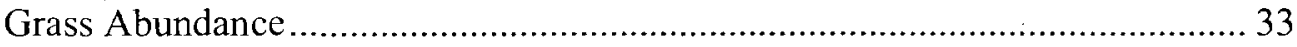

Burn Temperature Versus Vegetation Parameter Correlation and Follow-up............... 36

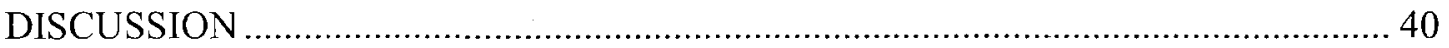

Overview of Vegetation Parameters ....................................................................... 41

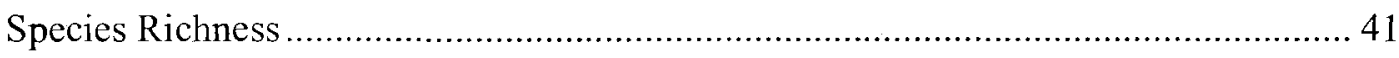

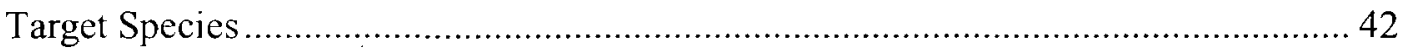

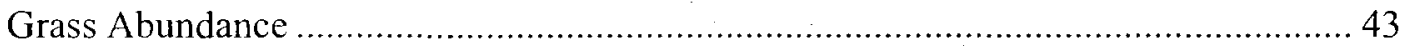

Change in Plantago erecta Correlated with Burn Temperature ................................... 44

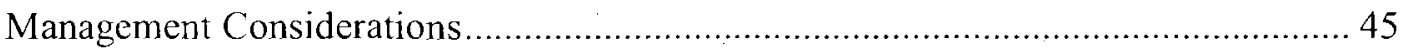

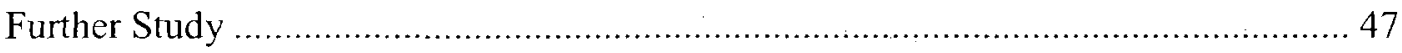

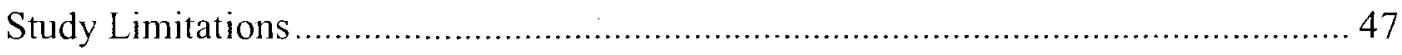

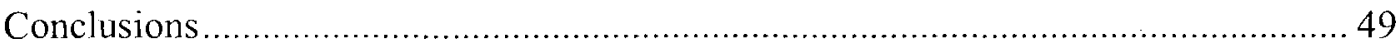

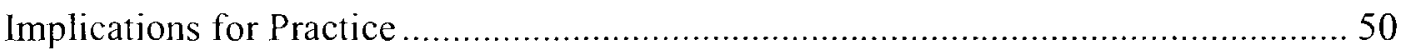

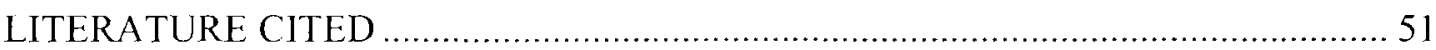

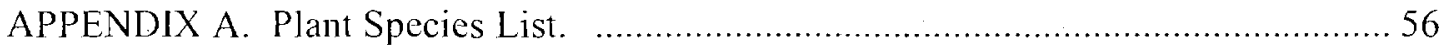




\section{LIST OF TABLES}

Table 1. Vegetation Parameters. ........................................................................ 23

Table 2. ANOVA p-values for L. ambiguus experiment parameters. Significant $p$-values are 0.10 for pre-burn pairing and 0.05 for treatment effect.

Table 3. ANOVA $p$-values for $B$. hordeaceus experiment parameters. Significant $p$-values are 0.10 for pre-burn pairing and 0.05 for treatment effect.................. 29

Table 4. Some parameters likely to explain opposing correlations were not significantly different. 36

Table 5. Correlation of change in P. erecta versus burn temperature at different burn temperatures 


\section{LIST OF FIGURES}

Figure 1. Location of study site at Rancho Cañada del Oro. A.) Santa Clara County, California. B.) California's position in North America. C.) Rancho Cañada del Oro (star), southeast of San Jose, CA in D.) Eastern Santa Clara County....... 5

Figure 2. Federally listed Bay checkerspot butterfly, observed in 2006 at study site. ..... 8

Figure 3. Vegetation on the serpentine outcrop is sparser and more diverse than on surrounding grasslands. Serpentine grassland is in the background. Exotic annual grassland, off the serpentine outcrop, is in the foreground.

Figure 4. Bee fly visiting L. ambiguus.

Figure 5. Leptosiphon ambiguus has thread-like stems and leaves. When flowers are closed, the plants are hard to see.

Figure 6. Distribution of Leptosiphon ambiguus. A.) Historical accounts of $L$. ambiguus. Voucher specimens available for all 14 counties, from Calflora 2009. B.) Current counties containing L. ambiguus, from CNPS 2009.

Figure 7. Patches identified in the L. ambiguus-rich experiment (top left photo) had more L. ambiguus (top right) and less B. hordeaceus (bottom right) than those in the "invaded" experiment (bottom left photo).

Figure 8. Distribution of plots on serpentine outcrop at Rancho Cañada del Oro study site.

Figure 9. Photo of burn box assembly.

Figure 10. Diagrammatic representation of quadrats and buffer zones. 20

Figure 11. A grass-invaded quadrat is ignited with a butane torch while radiant heat is measured with an infrared thermometer.....

Figure 12. Effect of burning on total species number in L. ambiguus-rich experiment. Species number was enhanced in burned quadrats when compared to controls. Error bars represent $\pm \mathrm{SE}$.

Figure 13. Effect of burning on exotic species richness in $B$. hordeaceus experiment... 31

Figure 14. Effect of burning on L. micradenia var. glabrata abundance in $L$. ambiguus rich experiment. Lessingia micradenia was suppressed in burned quadrats when compared to controls. Error bars represent $\pm \mathrm{SE}$. 
Figure 15. Effect of burning on L. ambiguus cover in 2006 in B. hordeaceus-invaded experiment. L. ambiguus cover increased in burned quadrats when compared to controls. Error bars represent $\pm \mathrm{SE}$

Figure 16. Effect of burning on $B$. hordeaceus abundance in $B$. hordeaceus invaded experiment. $B$. hordeaceus was suppressed in burned quadrats when compared to controls. *Frequency of subplots with $\geq 20$ plants. Error bars represent $\pm \mathrm{SE}$.

Figure 17. Effect of burning on native annual grass abundance in L. ambiguus-rich experiment. Error bars represent $\pm \mathrm{SE}$.

Figure 18. Effect of burning on native annual grass abundance in B. hordeaceusinvaded experiment. Error bars represent $\pm \mathrm{SE}$.

Figure 19. Mean exotic annual grass abundance in B. hordeaceus-invaded experiment. Error bars represent $\pm \mathrm{SE}$. 35

Figure 20. Mean total grass abundance in B. hordeaceus-invaded experiment. Error bars represent $\pm \mathrm{SE}$.

Figure 21. Plantago erecta versus burn temperature correlation. A.) In L. ambiguusrich quadrats, there was an increase in $P$. erecta abundance with higher burn temperatures. B.) In $B$. hordeaceus-invaded quadrats, the opposite occurred; there was a decrease in $P$. erecta abundance with higher burn temperatures

Figure 22. Change in P. erecta abundance in the L. ambiguus-rich experiment was correlated with pre-burn grass abundance of native grasses

Figure 23. Significant correlations with pre-burn grass abundances. In the $L$. ambiguus experiment, native perennial grass $(\mathrm{A})$ and native annual grass abundance $(C)$ are negatively correlated with burn temperature, while exotic annual grasses are positively correlated with burn temperature (B). In the $B$. hordeaceus experiment, combined native and exotic grass abundance is positively correlated with burn temperature (D). 


\section{Introduction}

Historically, serpentine grasslands have served as refuges for native grassland plant species (McNaughton 1968; Kruckeberg 1984; Mooney et al. 1986; Murphy \& Ehrlich 1989; Huenneke et al. 1990; Harrison 1997) and as habitat for endemic plants associated with serpentine soils (Kruckeberg 1984; Murphy \& Ehrlich 1989; U.S. Fish and Wildlife Service [USFWS] 1998). Even in serpentine soils, though, endemic plants have increasingly been displaced by non-native, invasive grasses and forbs (Heady 1977; Mooney et al. 1986). Serpentine grasslands have resisted invasion because only plants that have evolved on serpentine soil are adapted to serpentine soils' low levels of nutrients such as nitrogen, phosphorus, and calcium combined with high levels of magnesium, iron, and other metals that are toxic to many plants (Kruckeberg 1984; Huenneke et al. 1990).

Recently, however, serpentine grasslands are being threatened by encroachment of non-native plants. This expansion of exotics onto serpentine soil may be due to new adaptations (Harrison et al. 2001) or to changes in the environment such as increased nitrogen deposits in soil from car and truck emissions (Weiss 1999). Some studies have shown that nutrient-poor ecosystems are especially vulnerable to nitrogen deposition (Aerts \& Berendse 1988; Bobbink \& Roelofs 1995; Power et al. 1995). Additional threats to serpentine grassland species include habitat shrinkage due to land development, habitat fragmentation and disjunction (USFWS 1998).

Prescribed burning is one method in which managers control weeds and increase germination and growth of desired plants (Menke 1989; Thomsen et al. 1993; Barry 
1998; Bowcutt 1999; Pendergrass et al. 1999). Carefully executed burns can increase native plant cover or diversity (Menke 1989; Parsons \& Stohlgren 1989; Meyer \& Schiffman 1999). This shift in the community balance may result from a reduction in non-native plant biomass that results in increased space, light and nutrients (Vogl 1974; Parsons \& Stohlgren 1989; Whelan 1995; DiTomaso et al. 1999). Another possible mechanism is by slowing competitive displacement of native plants by exotic plants (McNaughton 1968; Noy-Meir 1995; Collins et al. 1998).

Following wildfires, Harrison et al. (2003) and Weiss and Wright (2005) conducted plant biodiversity studies in serpentine grasslands. These studies supported burning (and grazing) as a means of increasing native plant diversity and cover. Harrison's study, conducted in Yolo County, California, found that sites burned in an autumn wildfire contained greater species richness, particularly of native species, than unburned sites. Additionally, the burned sites had a less frequent occurrence of nonnative annual grasses, with the exception of Bromus hordeaceus (Soft chess). Weiss' and Wright's (2005) study, conducted in San Mateo and Santa Clara Counties, took advantage of a spring wildfire. They found that biodiversity and Plantago erecta (California plantain) cover increased and B. hordeaceus cover decreased.

An additional mechanism for increasing native plant species diversity and cover in serpentine grasslands may be volatilization of nitrogen during fires (Gundale 2001). Nitrogen is volatilized at temperatures as low as $200^{\circ} \mathrm{C}$; at $500^{\circ} \mathrm{C}$ and above, fifty percent or more of the nitrogen is volatilized (Neary et al. 1999). Nitrogen is most often volatilized in conditions with little organic matter or in very hot fires (Cilimburg \& Short 
2005; U.S. Forest Service 2005). In contrast, fires that burn large amounts of organic matter are likely to release nitrogen into the soil.

Nitrogen removal, whether by burning or grazing, may also benefit individual species. Weiss (1999) found that variability in nitrogen deposition and grazing regime both affected plant communities. In San Mateo and Santa Clara Counties, California, study sites had varying amounts of nitrogen deposition. In ungrazed sites with high nitrogen deposition, there was more non-native invasive annual grass, less of the anmual forb P. erecta, and fewer Euphydrya editha bayensis (Bay checkerspot butterflies) than in grazed sites with high nitrogen deposition. He proposed that high nitrogen leads to increased invasive grasses which grow tall and block $P$. erecta from detection by Bay checkerspot butterflies, a federally listed endangered species; $P$. erecta serves as the primary host plant for Bay checkerspot caterpillars (USFWS 1998).

In this controlled study, prescribed burning was investigated as a way of managing serpentine grasslands invaded by exotic grass. Two experiments were conducted: one investigated fire's impact on grassland patches rich with rare plant Leptosiphon ambiguus (Serpentine leptosiphon), the other examined effects on $L$. ambiguus patches invaded by exotic grass $B$. hordeaceus. Fire's impacts on species richness, key species, and grass abundance were examined by comparing pre- and postburn parameters. Key species, (described in detail below) included rare plants $L$. ambiguus and L. micradenia var. glabrata (Smooth lessingia), exotic grass $B$. hordeaceus, and butterfly host plant $P$. erecta. These species are of particular importance in the study system that was investigated. 


\section{Study System}

The study site is part of Rancho Cañada del Oro, located in California, U.S.A, approximately $11 \mathrm{~km}$ southeast of central San Jose (Fig. 1). Rancho Cañada del Oro is on the northeast (rain-shadow) side of the Santa Cruz Mountains, approximately $20 \mathrm{~km}$ northeast of the Pacific coast's Monterey Bay. The Santa Cruz Mountains were formed by tectonic action along the San Andreas Fault line. Serpentine outcrops, which are formed in fault zones, are found at Rancho Cañada del Oro. This serpentine soil is in the Montara series (United States Department of Agriculture 1974). Montara soil is a gray alkaline clay loam and is typically shallow, over greenish gray serpentine bedrock. Montara soils have low fertility and a low calcium:magnesium ratio (of 1:1 or less). The study site ranges in elevation from $365 \mathrm{~m}$ to $440 \mathrm{~m}$.

Santa Clara County has a Mediterranean climate with summer high temperatures averaging $29^{\circ} \mathrm{C}$ and winter lows averaging $10^{\circ} \mathrm{C}$ in San Jose (National Resource Conservation Center 2009). Mean annual rainfall is approximately $57 \mathrm{~cm}$ per year and occurs almost exclusively between October and April. Rainfall data for Rancho Cañada del Oro itself are not available before the 2003-2004 season, but the mountains typically receive more rainfall than the City of San Jose. At Rancho Cañada del Oro, the 20042005 season had 60.7 centimeters of rain, with 7 centimeters falling in March. During the 2005-2006 winter, there were 108 centimeters of rain with 44 centimeters falling in March and April.

Rancho Cañada del Oro (1571 ha) is owned and managed by Santa Clara County Open Space Authority (SCCOSA), an entity whose chief objective is to purchase and 


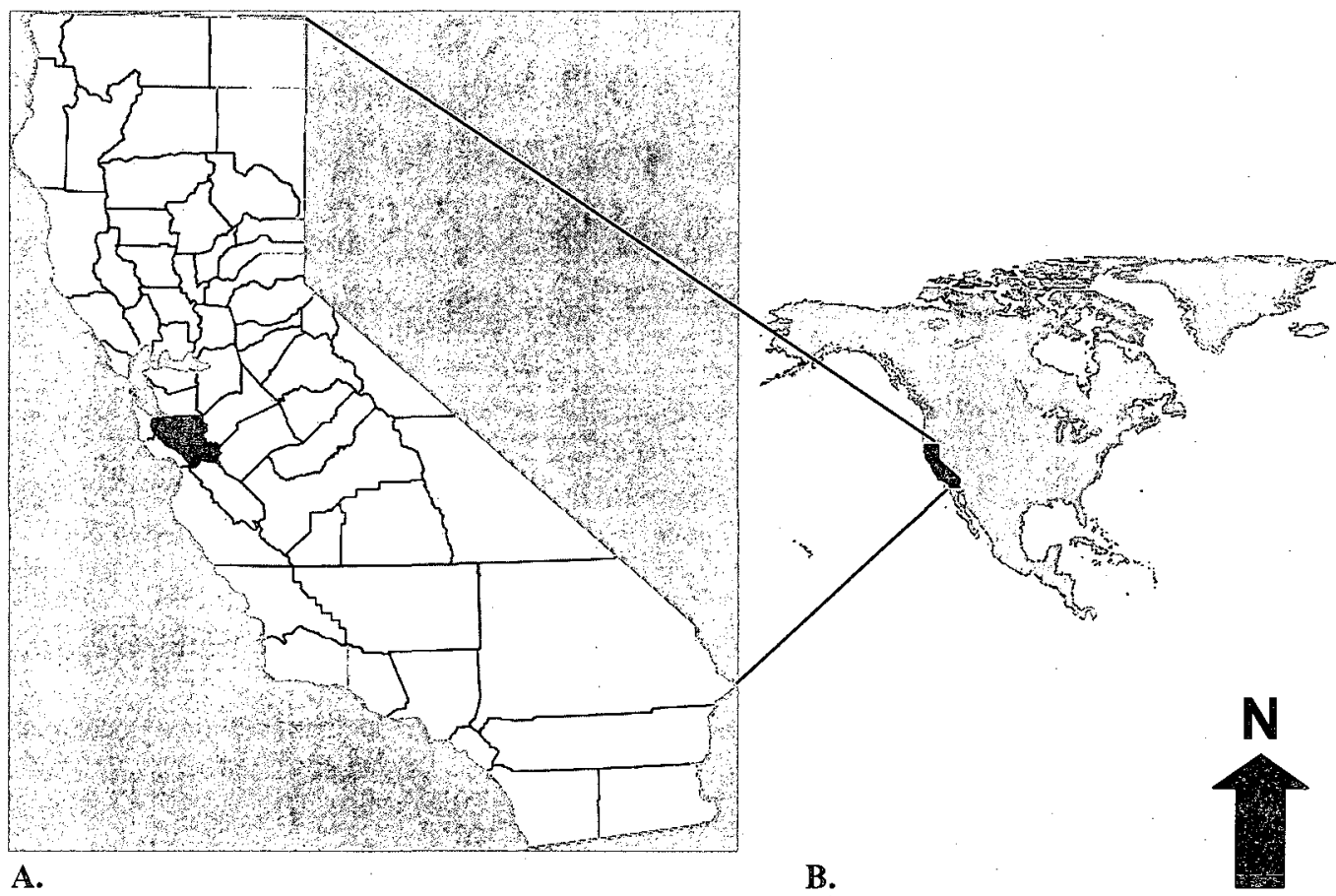

A.

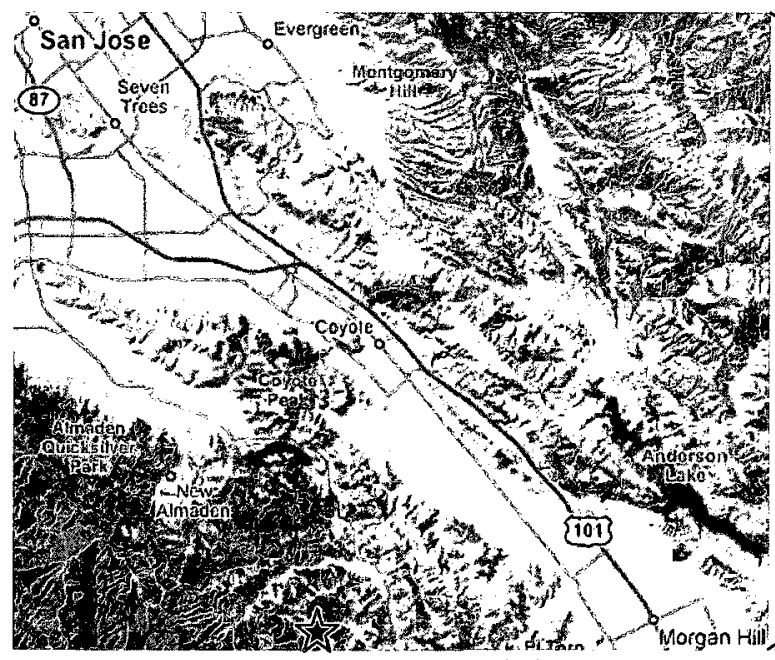

C. (C) Yahoo! Inc. All Rights Reserved.

Reprinted with permission.
B.

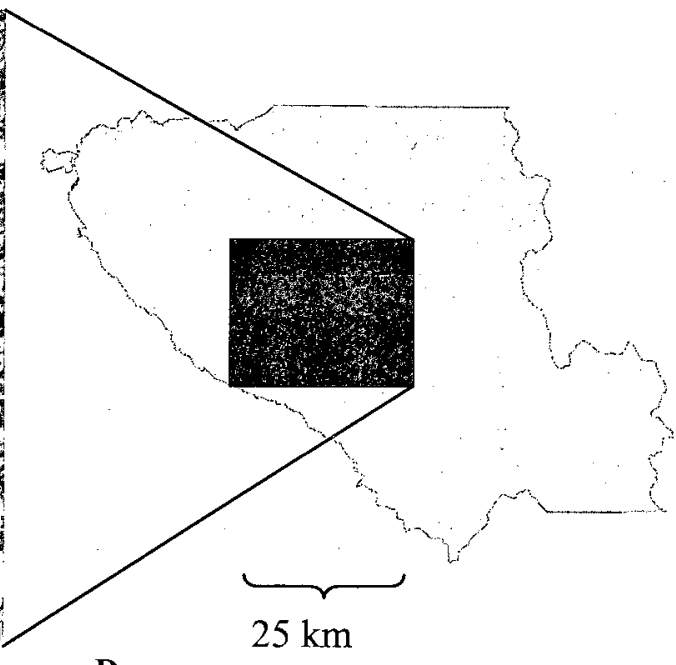

D.
$25 \mathrm{~km}$ 
conserve undeveloped lands. In 2004, the Open Space Authority designated Rancho Cañada del Oro as a preserve and has opened two trails. The study site is on the south side of Llagas Creek and Casa Loma Road. Surrounding properties include Calero County Park (a 1,407-ha hiking, horse-back riding, and water-sports park), cattle ranches, and large private properties. One main dirt road has been developed on the property that goes from the bottom of the preserve, a valley floor, to the ridge. There are smaller dirt roads that have not been maintained and are only suitable for four-wheel drive vehicles when it is dry and grass is not too high.

The southern portion of Rancho Cañada del Oro has been grazed for over 100 years and has a stock pond. Prior to 2004 , there were approximately 50 cows and calves on the property year round. (P. Congdon 2008, SCCOSA, San Jose, CA, personal communication). In 2004, SCCOSA started a formal grazing program. In an attempt to maintain 750 to 900 pounds/acre ( 840 to $1010 \mathrm{~kg} / \mathrm{ha}$ ) of residual dry vegetative matter, 28 to 32 cows and/or calves graze on the property for 7 to 9 months out of the year.

Study Site Fauna. Rare or threatened animals that are endemic to serpentine soils in California's San Francisco Bay Area include two species of blind harvestmen (harvestmen are commonly called daddy longlegs), five species of microblind harvestmen, a moth, and a butterfly. The study site is within the range of three of these species (USFWS 1998): Adela oplerella (Opler's longhom moth), Microcina homi (Hom's microblind harvestman), and the Bay checkerspot butterfly. The longhorn moth and harvestman are species of concern, and the Bay checkerspot butterfly is federally 
listed as a threatened species. The butterfly was observed during the course of this study (Fig. 2).

Study Site Flora. The plant communities found at Rancho Cañada del Oro are coast live oak woodland, manzanita and chamise chaparral, non-native annual grassland, perennial grassland, and riparian. These plant communities occur off serpentine and each appears to occur on serpentine as well.

The study site consists of patches of serpentine grassland on a small (approximately 8-ha) isolated outcrop of serpentine soil located on Rancho Cañada del Oro. Native plants that dominate the grassland patches are typical of California serpentine grasslands. Plants include perennial grasses such as Nasella pulchra (Purple needlegrass), Melica torreyana (Torrey's melicgrass), Melica californica (California melicgrass); perennial forbs such as Dichelostemma capitatum (Blue dicks); and annual forbs such as P. erecta, Lasthenia californica (California goldfields), and Layia gaillardioides (Woodland tidytips). As is typical of serpentine grasslands, study site vegetation is diverse and sparser than other grasslands (Bowcutt 1999) (Fig. 3).

Native species at the study site include serpentine grassland endemics. These plants are California Native Plant Society (CNPS) designated rare plants, but are not federally listed. The rare serpentine grassland endemics found at the study site are Leptosiphon ambiguus (List 4.2), Lessingia micradenia var. glabrata) (List 1B.2), and Streptanthus albidus peramoenus (Most beautiful jewelfower) (List 1B). Dudleya abramsii setchellii (Santa Clara Valley liveforever) was intentionally avoided 


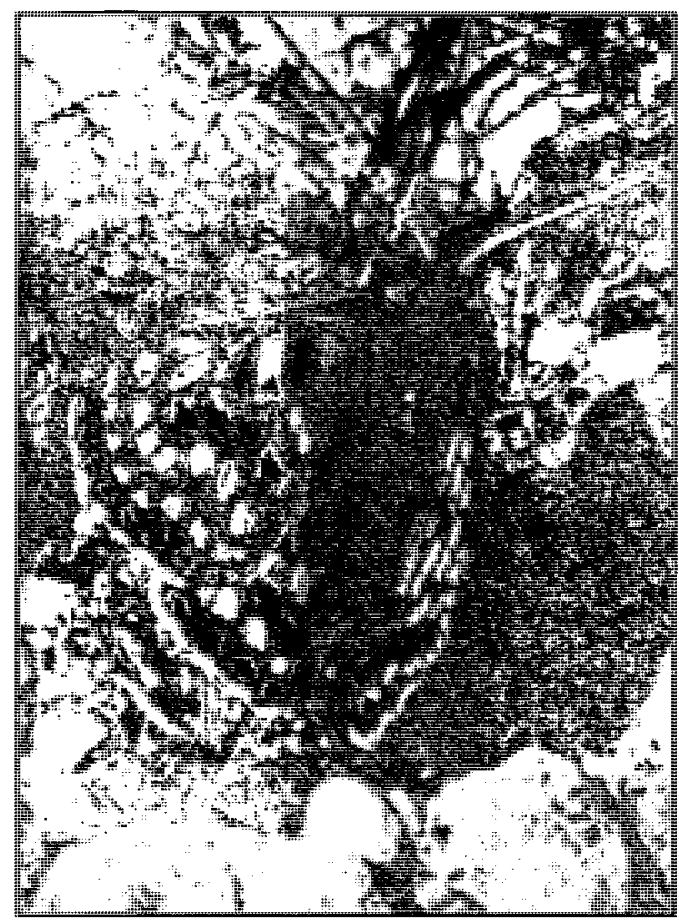

Figure 2. Federally listed Bay checkerspot butterfly, observed in 2006 at study site.

because it is a federally listed endangered plant. In any case, it did not occur in close proximity to L. ambiguus (one of the primary species assessed in this study). None of the study quadrats included $S$. albidus because there is only one small patch $\left(<10 \mathrm{~m}^{2}\right)$ of it at the study site.

At the study site, native-rich and native-depauperate patches occur within the serpentine grassland area. Grasses are by far the most common invasive exotics at the site (based on area covered). The grass $B$. hordeaceus is almost ubiquitous; however, within the areas that are native-rich, it is much less dense. Avena barbata (Slender wild oats) grows on the fringes of and within patches of the native-rich areas; Lolium multiflorum (Italian ryegrass) is almost entirely restricted to the margins of the serpentine 


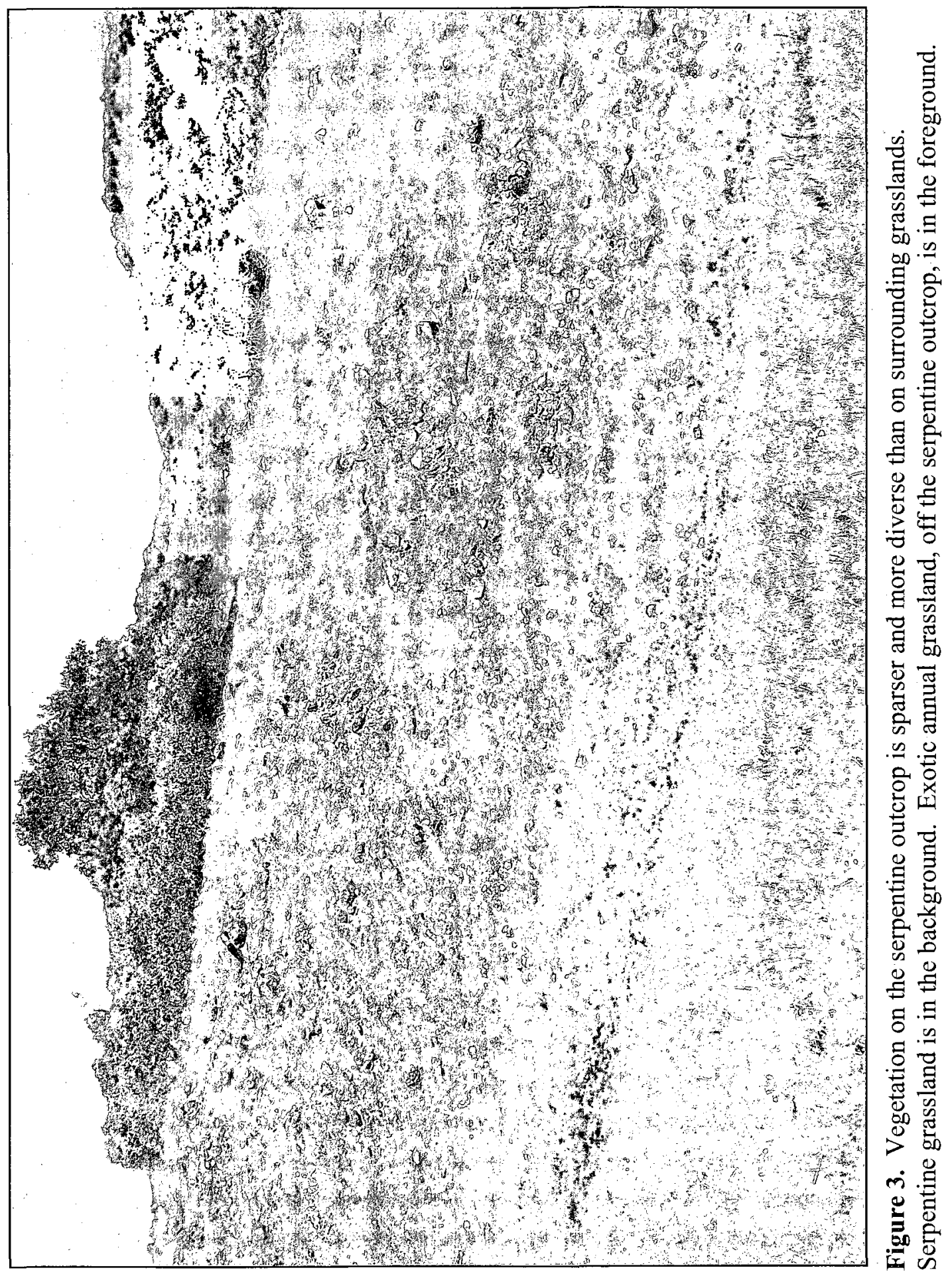


outcrop. At this site, L. ambiguus was restricted to native-rich areas, while L. micradenia var. glabrata grew in these areas and in the areas that were invaded by the wild oats.

Leptosiphon ambiguus (Rattan) J.M. Porter and L.A. Johnson is in the Polemoniaceae (Phlox) family (Hickman 1993). The name was recently changed from Linanthus ambiguus to Leptosiphon ambiguus as were most of the species in the genus Linanthus that are found in California. Reclassification was due to genetic studies by Bell, Patterson, Porter and Johnson (Porter 1998; Porter \& Johnson 2000; Bell \& Patterson 2000). The old generic name, Linanthus, comes from two Greek words: linon, meaning flax, and anthos, meaning flower because of the flower's likeness to flax. The new generic name comes from lepto which means thin, and siphon which means tube. Leptosiphon ambiguus is an herbaceous (non-woody) annual dicot (Hickman 1993). The flower has a tubular corolla which usually has five lobes (petals). Leptosiphon ssp. ovules are self-pollinated or cross pollinated by wind or insects, especially the bee fly (Bombylius spp., Bombyliidae) (Schmidtt 1980; Murphy \& Ehrlich 1989; Goodwillie 1999). Murphy and Ehrlich once observed Bay checkerspot butterflies visiting $L$. androsaceus when bee flies did not emerge until late in the season. Nectar had risen in the corolla to a level accessible to the butterfly's shorter proboscis. Bee flies were the only insects observed visiting $L$. ambiguus during the course of this study (Fig. 4). The flies have a long proboscis that extracts nectar from the long tubular flower. The $L$. ambiguus fruit is a capsule which dehisces (pops) when ripe to release seeds. Stems and leaves are thread-like, making it difficult to see when flowers are closed (Fig. 5.) 


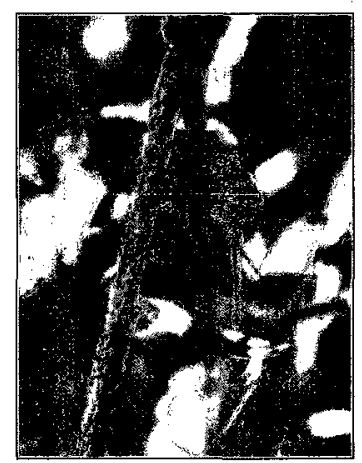

Figure 4. Bee fly visiting L. ambiguus.

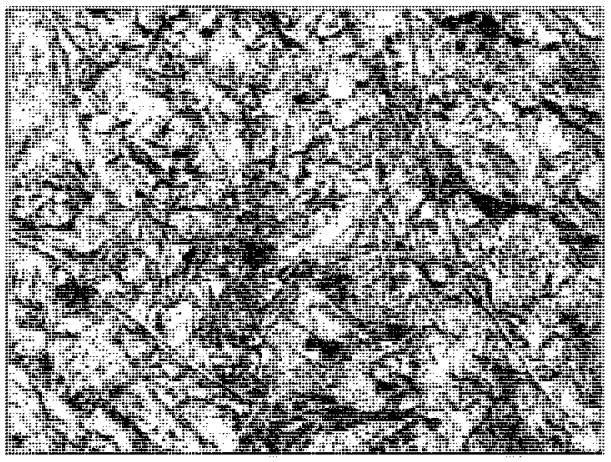

Figure 5. Leptosiphon ambiguus has thread-like stems and leaves. When flowers are closed, the plants are hard to see.

Leptosiphon ambiguus is found below 1000 meters above sea level in grassy areas, and is restricted to serpentine soils. Its affinity to serpentine soil is 5.8 on a scale of 1.0 to 6.25 with 6.25 showing the strongest affinity to serpentine (Safford et al. 2005). Leptosiphon ambiguus is endemic to California's San Francisco Bay Area and the Inner South Coast Ranges (Hickman, 1993) within nine counties (CNPS 2009), although it has been found, at least historically, in 14 counties (Calflora 2009) (Fig. 6). Because of its restriction to serpentine soils and limited range, it is on the CNPS watch list. Its state and global statuses are S3.2 and G3, respectively; it is "fairly endangered" and found only in California with an estimated 21-80 occurrences on 10,000-50,000 acres (4,047-20,234 ha) (California Native Plant Society 2009). 


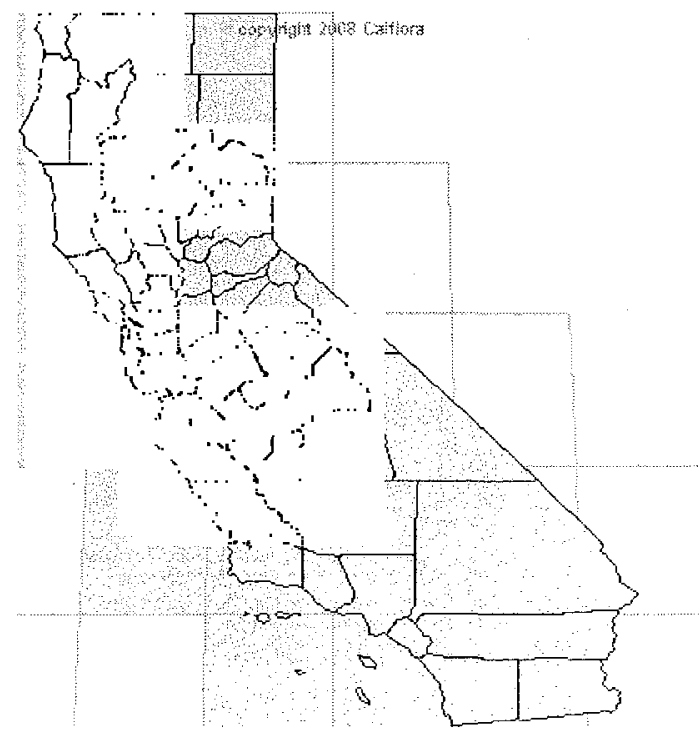

A. Reprinted with permission from Calflora. (C) Calflora 2008

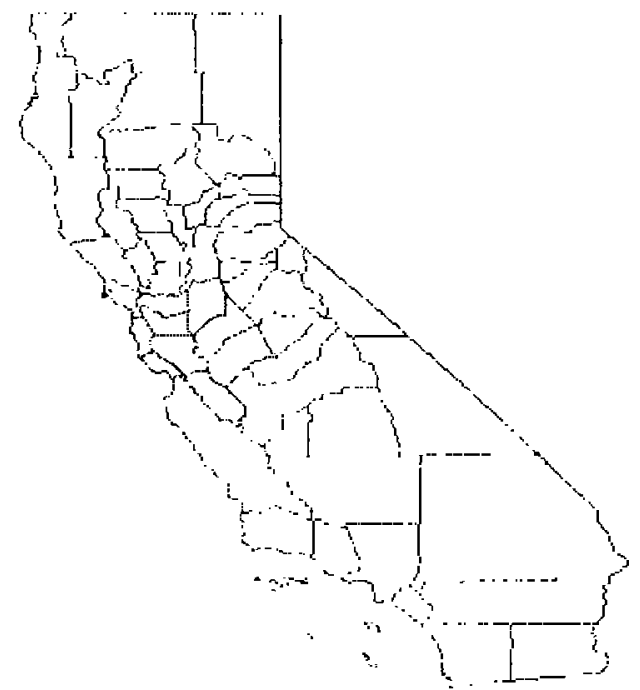

B. Reprinted with permission from CNPS. (C) CNPS 2009

Figure 6. Distribution of Leptosiphon ambiguus. A.) Historical accounts of $L$. ambiguus. Voucher specimens available for all 14 counties, from Calflora 2009. B.) Current counties containing L. ambiguus, from CNPS 2009.

\section{Hypothesis and Goals}

I chose to conduct my study in the less-invaded areas and to concentrate on management of L. ambiguus. I targeted control of B. hordeaceus, which, in prime habitat areas, seemed to be most competitive with native plants in general, and with L. ambiguus in particular. I chose to do this because I thought that management of these areas would most likely produce positive results partly because there would be an intact native seed bank. Also, MacArthur and Wilson (1967) demonstrated that islands with larger areas supported more species than a combined equal area of small but similar 
islands. This island biogeography principle has been applied to patches of isolated habitat (islands) such as serpentine outcrops (Harrison et al. 2001). Employing this principle, it is better to enlarge a patch (of native serpentine grassland species) than it is to work from the edges to create several smaller but divided patches. Finally, habitat edges and small patches are more quickly invaded because of increased propagule arrival from the outside (Harrison et al. 2003).

In this study, I hypothesize that is that prescribed, early summer burning would enhance natives and reduce exotic invasive plant abundances in serpentine grasslands. One aim was to perform this study with randomly assigned controls; previous studies were conducted on sites where wildfires occurred. The two main goals were to determine if burning would affect the abundance of rare plant L. ambiguus, either positively or negatively, within its current habitat and to determine if burning will reduce non-native annual grass, $B$. hordeaceus. Another goal was to see if two other target species, $L$. micradenia var. glabrata and P. erecta, changed in abundance due to the burn. Lessingia micradenia was studied because of its rare status in California; $P$. erecta was studied because it is the primary host plant of the endangered checkerspot butterfly. Other objectives were to determine whether native and/or exotic species richness and/or grass abundance was affected by fire. The final goal was to determine whether or not burn temperature was correlated with the effects of burning on any of the vegetation parameters. 


\section{Methods}

\section{Experimental Design}

Identifying and Pairing Quadrats. Serpentine grassland patches were identified in the study by the presence of serpentine grassland endemic plants (Leptosiphon ambiguus, Lessingia micradenia var. glabrata, and Streptanthus albidus peramoenus). In spring, serpentine patches that are L. ambiguus-rich are visually very different from patches that are invaded by $B$. hordeaceus. These "L. ambiguus" patches have a high percent cover of $L$. ambiguus throughout much of the quadrat. " $B$. hordeaceus" patches have a higher abundance of B. hordeaceus and less L. ambiguus (Fig. 7).

First, during quadrat selection, small $(1 \times 1-\mathrm{m}$ or slightly larger $)$ patches of $L$. ambiguus were identified and marked with flags. From these patches, ten $1 \times 1-\mathrm{m}$ L. ambiguus-rich master quadrats were chosen. A $1 \times 1-\mathrm{m}$ quadrat-marker made of PVC tubing, with 36 equal subplots marked off with monofilament line in a $6 \times 6$ grid, was laid down on the patch. Within master quadrats, 33-36 subplots contained L. ambiguus, with no more than four of the subplots containing 20 or more $B$. hordeaceus plants (these were counted by identifying culms or flowering stalks). Master quadrats were paired with quadrats that had approximately the same abundance (within 3 subplots, or $8.3 \%$ ) of L. ambiguus and B. hordeaceus.

Quadrats were also paired by proximity; pairs were located within $10.5 \mathrm{~m}$ of each other. Where possible, they were also visually paired by presence and abundance of other dominant plant species. Where adequate matches could not be found, the quadrats 

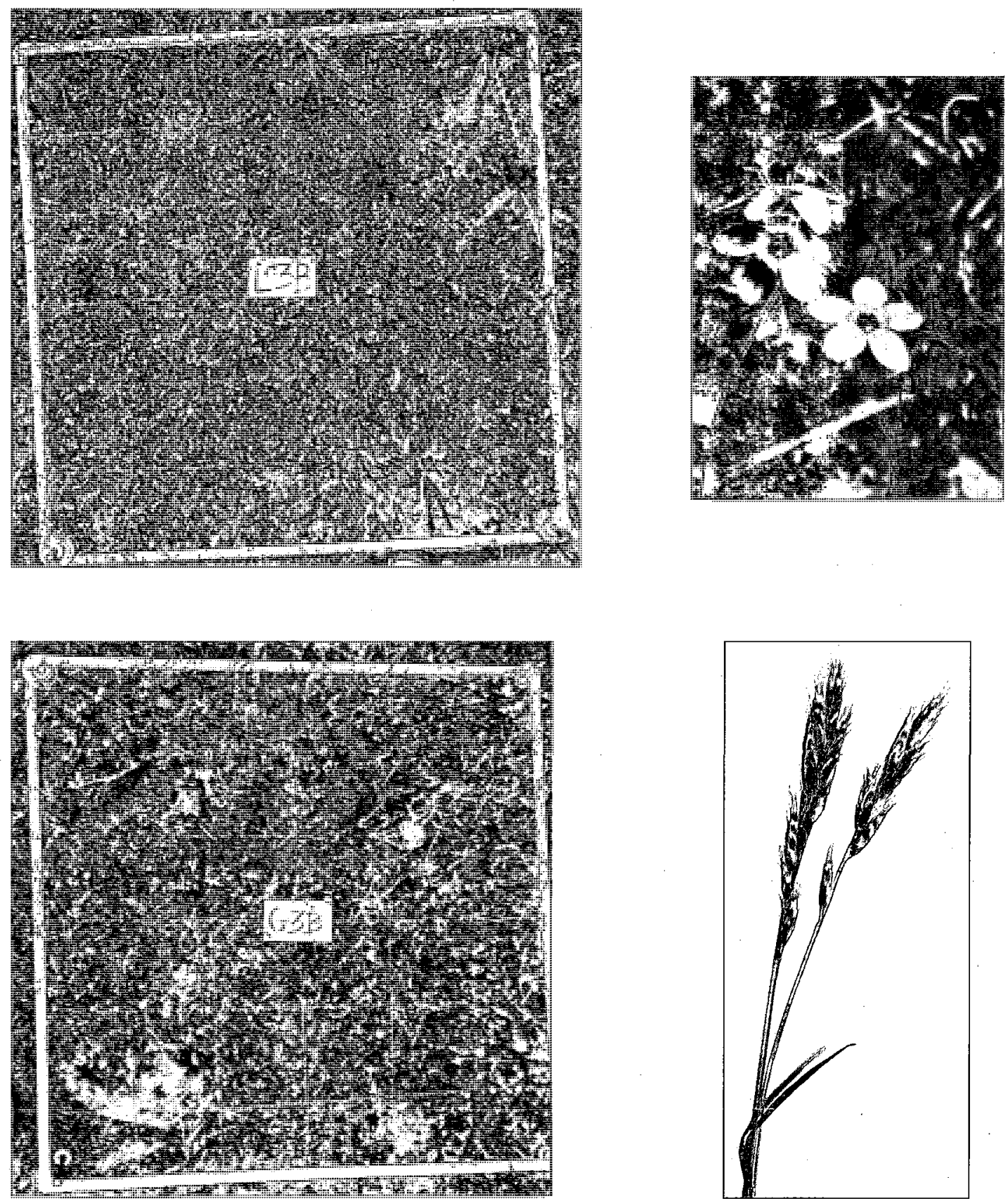

Figure 7. Patches identified in the L. ambiguus-rich experiment (top left photo) had more L. ambiguus (top right) and less B. hordeaceus (bottom right) than those in the "invaded" experiment (bottom left photo). 
were discarded. New master quadrats were selected from among the previously identified small patches and these patches were subjected to the pairing criteria until ten pairs of $L$. ambiguus-rich quadrats were found (Fig. 8).

Similarly, ten $B$. hordeaceus-invaded master quadrats were chosen from flagged patches and paired with similar quadrats for a total of 40 quadrats. Bromus hordeaceus quadrats were identified and chosen on the fringes of L. ambiguus-rich areas, because patches close to L. ambiguus-rich areas were thought to be more likely to have a similar seed bank that would respond to the burns more than distant quadrats would. Bromus hordeaceus quadrats were chosen so that a similar number of subplots contained $L$. ambiguus as contained a high density of $B$. hordeaceus. Master quadrats had 15-28 subplots containing L. ambiguus, and 15-28 subplots that contained 20 or more culms of B. hordeaceus. Pairs were matched to within 3 subplots (8.3\%) of $L$. ambiguus and to within 2 subplots (5.5\%) of $B$. hordeaceus. Paired quadrats were within $7.5 \mathrm{~m}$ of each other (Fig. 8).

Quadrats were also paired by visually estimating percent cover of $L$. ambiguus. However, this measure was not recorded because of the difficulty of consistently and accurately estimating $L$. ambiguus cover. Percent cover was easy to estimate when L. ambiguus flowers were open, but when they were closed because of wind or senescence they were hard to see and still harder to distinguish from L. linaflorus and from other species that resemble $L$. ambiguus. This was especially true when estimating percent cover for the whole quadrat or even a quarter of a quadrat at a time. Even though 
L. ambiguus cover was not measured in order to pair quadrats, percent cover appeared to be matched within pairs. Therefore, the abundance measure used ( $\%$ subplots/quadrat) seemed to capture the difference in the amount of $L$. ambiguus within pairs prior to the burn.

After the burn, it was clear that the L. ambiguus frequency measure alone no longer accurately portrayed differences in L. ambiguus abundance within pairs. For each subplot relative cover was estimated on a scale from $0.0-4.0$ with a precision level of 0.25. A value of "4" denoted that the entire subplot was dense with L. ambiguus. Maximum relative cover for a quadrat would be 144 . This value was converted to a percentage.

Because quadrats were chosen to represent $L$. ambiguus-rich areas and L. ambiguus areas that are adjacent to B. hordeaceus, they are not distributed randomly throughout the grasslands. They are clumped in areas that meet these requirements (Fig. 8). Quadrats were marked with flags. Corners of quadrats were marked with 1-inch washers, held in place with 8-inch nails.

\section{Treatment}

Summary of Burn Protocol and Description of Burn Boxes. The burns were completed within burn boxes, 1.5 -m square, 80 -cm high metal frames, made from 24 gauge steel sheets and held together with bolts and wing nuts as described by Bruce Pavlik (2004, Department of Biology, Mills College, Oakland, CA, personal communication) (Fig. 9). 


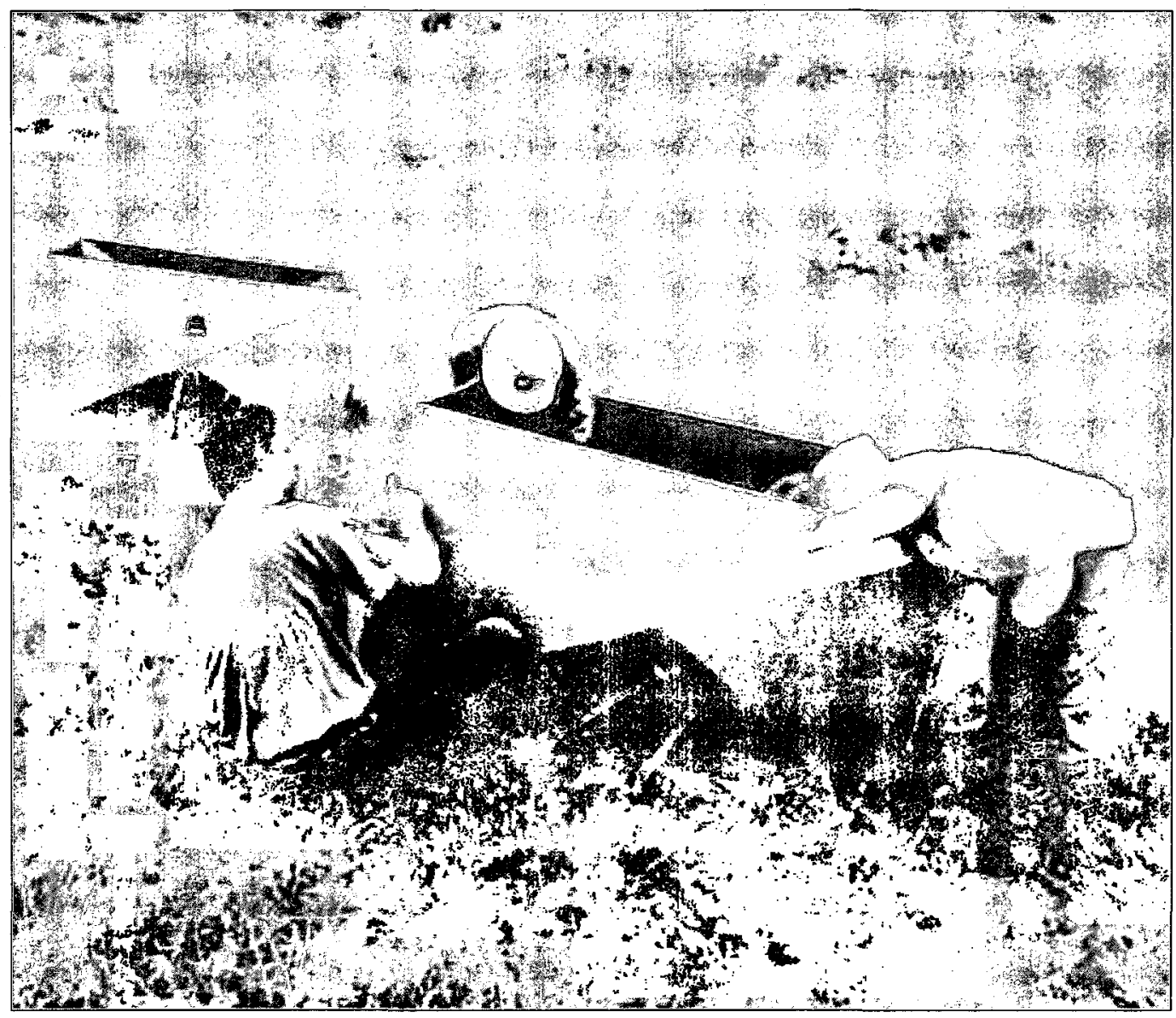

Figure 9. Photo of burn box assembly. Printed with permission from Chris Brinegar.

Buffer zone. In order to decrease edge effects, such as seeds falling into burned areas from outside the quadrats, $0.5-\mathrm{m}$ buffer zones were created (Fig. 10). For "burned" quadrats, a $1.5 \times 1.5-\mathrm{m}$ area, with the sampled area in the center, was burned within the burn boxes. This created a $0.25-\mathrm{m}$ burned buffer zone on each edge. The buffer zone was slightly increased to $0.5 \mathrm{~m}$ by mowing around the burn box to a $2 \times 2$-m-perimeter before performing the burns. The control quadrats had a $0.5-\mathrm{m}$ buffer zone that was not burned or otherwise altered. 
Unburned Quadrats-Control

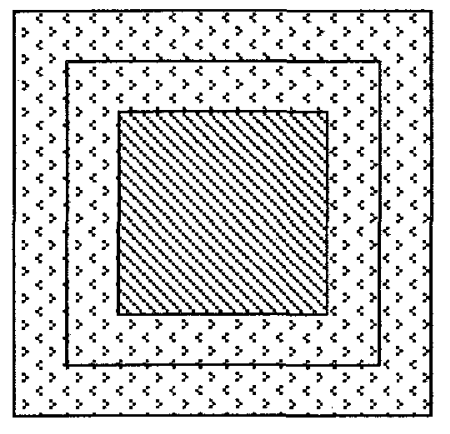

W Sampled $\begin{aligned} & {\left[\begin{array}{l}3 \\ 2 \\ 3\end{array}\right.} \\ & 3\end{aligned}$
Burned Quadrats-Treatment

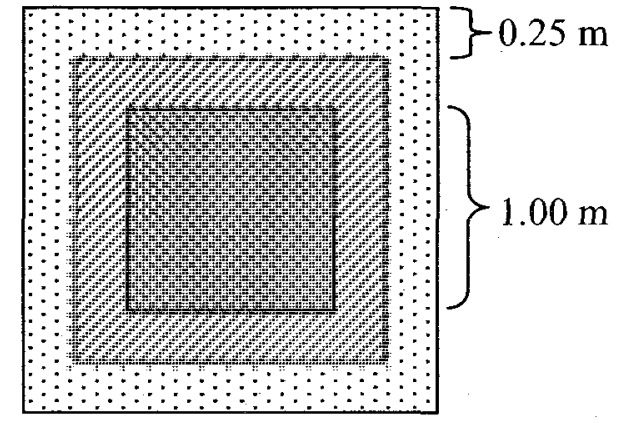

\section{Burned}

and sampled
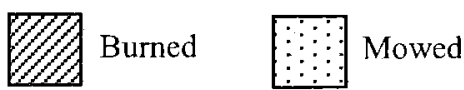

Figure 10. Diagrammatic representation of quadrats and buffer zones.

Timing and Burn Conditions. From each pair of quadrats, one was randomly chosen to be burned in early summer, when the grass was dry enough to burn, before $B$. hordeaceus and other exotic annual grasses had dropped their seeds, and after most $L$. ambiguus plants were senescent. The other quadrat from each pair was not burned. Santa Clara County Open Space Authority received permission from Santa Clara County to perform the burns on 28 June, 2005.

Weather conditions were monitored throughout the burn day in order to assess fire danger and burn conditions. The burn was performed on a calm morning between 8:20 and 11:15am; wind speeds varied between 0 and $3.5 \mathrm{mph}(5.6 \mathrm{~km} / \mathrm{h})$. The temperature increased from 15 to $23^{\circ} \mathrm{C}$, while relative humidity decreased from 88 percent to 57 percent. Radiant ground temperature, measured with an infrared thermometer (Extech, 
Inc., Waltham, MA, U.S.A.), generally increased during the morning from a low of $18.3^{\circ} \mathrm{C}$ to a high of $42^{\circ} \mathrm{C}$. A test burn was performed in order to gauge the hazard of the fire's escaping the burn box and in order to assess and fine-tune the burn protocol. Performing the Burn. Vegetation was ignited with a hand-held butane torch. In an attempt to more completely burn vegetation and to create conditions similar to prescribed burns performed in the open, we "back-burned" the quadrats. The vegetation at the top of the quadrat was ignited. We let the fire move down through the quadrat. The burn boxes seemed to block the air, and therefore the fire, from moving through the quadrat. The top-most unburned portion of the quadrat was re-ignited as needed. A backpack style pressurized water mister was used to extinguish flames that escaped beneath the burn box. Burn boxes were kept in place until each fire died out (Fig. 11).

Fire temperature was measured with the infrared thermometer held at arm's length by the same person in more or less the same position above each quadrat. A high temperature for each quadrat was recorded. These temperatures ranged from 276 to $646^{\circ} \mathrm{C}$ in L. ambiguus-rich quadrats and from 411 to $683^{\circ} \mathrm{C}$ in $B$. hordeaceus invaded quadrats. We attempted to measure ground-level burn temperature with temperature measuring crayons (Omega Engineering, Inc., Stamford, CT, U.S.A.) as described by Meyer and Schiffman (1999) without success. 


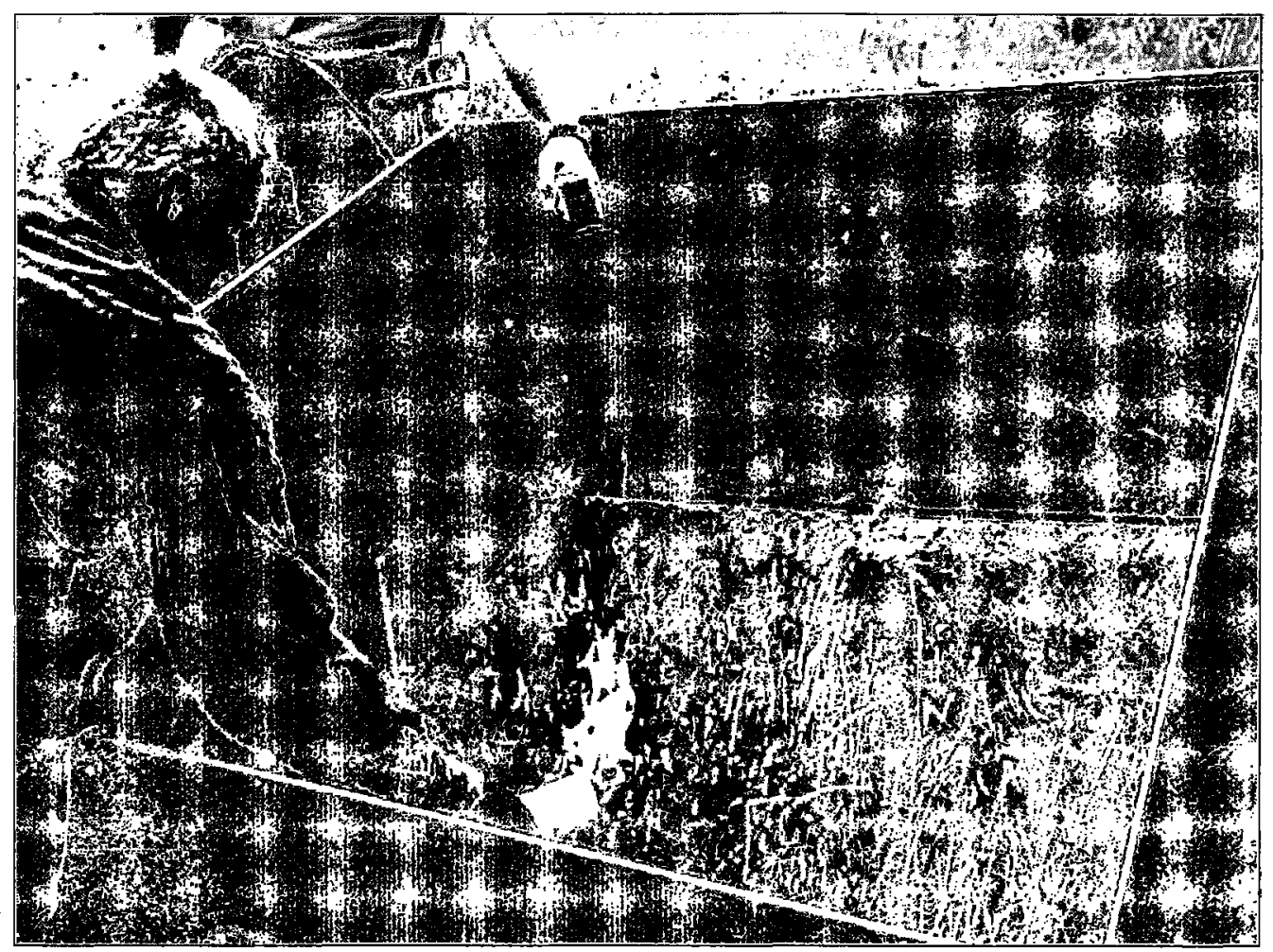

Figure 11. A grass-invaded quadrat is ignited with a butane torch while radiant heat is measured with an infrared thermometer. Printed with permission from Chris Brinegar.

\section{Data Collection}

Vegetation parameter data were collected (Table 1) by working from a data sheet with a list of plants previously found in local serpentine grasslands. Each species was recorded as it was found; species not on the original list were added to it. (Previously sampled quadrats were double-checked for these species). A specimen of each unrecognized species was collected. These species were temporarily recorded as "Species A," "Grass B," "Asteraceae C," etc. and were identified later. 
Table 1. Vegetation Parameters.

\section{Target Species Parameters}

Leptosiphon ambiguus Abundance (/36)

Leptosiphon ambiguus Relative Cover (/144)

Bromus hordeaceus Abundance

Lessingia micradenia var. glabrata Abundance

Plantago erecta Abundance

Grass Abundance Parameters

Native Grass Abundance

Exotic Grass Abundance

Perennial Grass Abundance

Annual Grass Abundance
Species Richness Parameters

Native Species Richness

Native Grass Richness

Native Forb Richness

Exotic Species Richness

Exotic Grass Species Richness

Total Species Richness

Total Grass Abundance

Richness was determined by counting the number of species found in each quadrat; plants were grouped into life-form categories (grass or forb) and origin (native or exotic). For target species (L. ambiguns, B. hordeaceus, L. micradenia, and Plantago erecta) frequency, was also recorded; the number of subplots (out of 36) containing each target species was counted and converted to a percentage of the total number of subplots per quadrat. Frequency was considered to be an estimate of abundance for target plants because these species had relatively even densities in subplots where they occurred. 
Grass abundance was measured by recording subplot frequency for each species of grass. In addition to grouping species together by origin, they were grouped together by habit (annual, perennial). The frequencies were added together and converted to a percentage for each group and for all grasses combined. (Grasses could add up to more than 100 percent since more than one type of grass could occur in each subplot.)

Two sets of vegetation parameter data were collected, one before, and one after the burn. In 2005, species data were collected between 15 April and 12 May. In 2006, data were collected between 19 April and 12 May.

Many of the quadrats were disturbed to a moderate degree by gophers, cows, or (in three cases) ATVs before data collection the second year. Because the quadrats were so small, there was a concern that the missing data would unduly influence the measured effect that would be attributed to burning. The estimated degree of disturbance was tested to see if burned quadrats were disturbed more or less than their paired controls. The two measures of disturbance were percent frequency of subplots that were disturbed and the percent cover of bare ground due to disturbance. It was not possible to determine the degree of disturbance for cattle, gophers, and ATVs separately, because rain or any of the disturbers erased underlying evidence. However, whatever the cause of the disturbance, it was still possible to identify areas of bare soil that were at one time disturbed to the point that they had little or no vegetation on them.

\section{Data Analysis}

In preliminary tests, initial mean species richnesses and abundances, "vegetation parameters," (Table 1) and mean disturbance were analyzed for differences between pairs 
(blocks) for each experiment. The two experiments were on L. ambiguus-rich quadrats and $B$. hordeaceus-invaded quadrats. For each vegetation parameter, one-way Randomized Block ANOVAs (Zar 1984) were used to determine if mean richness or abundance in the paired treatment sites were similar prior to treatment. Pair and burn treatment were the independent variables. There were ten pairs and two treatments (preburn and control) in each experiment; $p<0.10$ was considered to reflect differences between means. For each experiment, a one-way Randomized Block ANOVA (Zar 1984) was used to determine if the mean degree of disturbance was different $(p<0.10)$ in burned quadrats than controls. Independent variables were pair and treatment.

One-way Randomized Repeated Measure Block ANOVAs (Zar 1984) were used to determine if there was a treatment effect $(p<0.05)$ on mean species richness or abundance parameters. The independent variables were pair, treatment, and time. There were ten pairs, two treatments (burn and control) and two time-levels (spring 2005 and spring 2006) for each vegetation parameter. Each of the above analyses was run independently for the L. ambiguus experiment and the B. hordeaceus experiment. Pearson correlation coefficients were determined (Zar 1984) to see if there were correlations between burn temperature and the change in each species richness or plant abundance between years $(|r|>0.6)$; L. ambiguus and B. hordeaceus experiments were tested both separately and together. Where one experiment showed a positive correlation between burn temperature and a given vegetation parameter, and the other experiment showed a negative correlation, there was further investigation. 
In follow-up investigations, differences that might explain why a change in abundance was positively correlated with burn temperature in one experiment but negatively correlated in the other experiment were examined. Separate one-way Randomized ANOVAs tested for differences in mean pre-burn parameter values, change in parameter, and burn temperature between experiments. Correlation was tested between change in parameter and burn temperature using different burn temperature ranges designated as "cool" and "hot" in a combined L. ambiguus and B. hordeaceus experiment to see if there was a break in burn temperature where the parameter changed from a positive correlation to a negative correlation.

Further correlation tests were run to see if there were differences between experiments that would explain a positive correlation of burn temperature with a vegetation parameter in one experiment and a negative correlation in the other experiment. Pre-burn grass abundance seemed the most likely parameter to affect burn temperature, so it was tested for correlation with burn temperature for $L$. ambiguus and $B$. hordeaceus experiments separately and together. Correlation between change in parameter and pre-burn grass abundance and between change in parameter and change in grass abundance were also tested. Follow-up investigations were conducted on burned quadrats only, since only burned quadrats had associated burn temperatures. If there were significant results in tests that were relevant to control quadrats, they would have been further investigated as well. 


\section{Results}

\section{Overview of Study Quadrat Vegetation}

Sixty-eight plant species were identified in study quadrats during the course of the study: 55 native species and 13 exotics (Appendix A). Initially the Leptosiphon ambiguus patches had 41 native and nine exotic plant species. Species richness for the Bromus hordeaceus patches was 47 native and 8 exotic plant species. Eight plants were found in 2006 that were not found in 2005. One plant that had occurred in 2005 was not found in 2006.

Although virtually the same numbers of exotic species were in both experiments the first year, they were present in significantly different quantities. The mean number of exotic species was higher in the B. hordeaceus-invaded experiment than in the $L$.

ambiguus experiment. Exotic annual grasses were significantly more abundant in the $B$. hordeaceus experiment than in the L. ambiguus experiment $(p<0.001)$. Native annual grass, Vulpia microstachys (Small fescue), was not significantly different in the two experiments $(p<0.001)$. Native species richness and abundance parameters were not significantly different between the two experiments. The B. hordeaceus-invaded patches included more exotic plants, but the L. ambiguus-rich experiment did not include more natives (keeping in mind that abundance was not measured for most native species).

\section{Preliminary Analyses: Initial and Disturbance Parameters}

In L. ambiguus-rich quadrats, the Block ANOVAs showed that none of the initial parameters were significantly different in burned quadrats than in controls (Table 2, first column). Neither disturbance frequency $(p=0.367)$ nor disturbance cover $(p=0.184)$ 
Table 2. ANOVA $p$-values for L. ambiguus experiment parameters. Significant $p$-values are $\underline{0.10}$ for pre-burn pairing and $\underline{\mathbf{0 . 0 5}}$ for treatment effect.

Pre-burn Repeated Measure

(Treatment) (Time $\mathrm{x}$ Treatment)

\section{Target Species}

\begin{tabular}{|c|c|c|}
\hline L. ambiguus, \% Subplot Frequency & 0.168 & 0.454 \\
\hline L. ambiguus, \% Cover & $\mathrm{n} / \mathrm{a}$ & 0.531 \\
\hline B.hordeaceus, \% Subplot Frequency & 1.000 & 0.285 \\
\hline L. micradenia, \% Subplot Frequency & 0.746 & $\underline{0.016}$ \\
\hline P. erecta, \% Subplot Frequency & 0.903 & 0.099 \\
\hline
\end{tabular}

\section{Grass Abundance}

Native Perennial Grass Abundance,

$0.270 \quad 0.262$

$\%$ Subplot Frequency

Native Annual Grass Abundance,

0.159

$\underline{0.027}$

$\%$ Subplot Frequency

Exotic Annual Grass Abundance,

$\%$ Subplot Frequency

$\begin{array}{ll}0.133 & 1.000\end{array}$

Total Grass Abundance,

0.166

0.129

$\%$ Subplot Frequency

\section{Species Richness}

Native Species Richness, no. spp.

0.688

0.207

Native Grass Richness, no. spp.

0.705

0.322

Native Forb Richness, no. spp.

0.759

0.124

Exotic Species, no. spp.

0.260

0.743

Exotic Grasses, no. spp.

0.496

0.853

Total Species, no. spp.

1.000

$\underline{0.048}$

o Single measurement post-burn, not repeated 
were significantly different in burned quadrats than in controls. In $B$. hordeaceus quadrats, initial parameters differed somewhat significantly between control and burned quadrats $(0.05<p<0.10)$ (Table 3 , first column). Neither mean disturbance frequency nor mean disturbance cover were significantly different $(p=0.167$ and 0.446$)$ in burned quadrats than controls. Because differences were not significant, neither disturbance measure was used as a covariate in the Repeated Measure ANOVA analysis of the vegetation parameters for either the $L$. ambiguus or the B. hordeaceus experiment.

\section{Effects of Burning on L. ambiguus and B. hordeaceus Quadrats}

In L. ambiguus quadrats three parameters were significantly affected by burning (Table 2, second column). In $B$. hordeaceus quadrats, six parameters were significantly dependent on treatment (Table 3, second column).

Species Richness. In L. ambiguus quadrats, burned quadrats had significantly more species (natives and exotics combined) than controls $(p=0.048)$ (Fig. 12). In the $B$. hordeaceus experiment, the mean number of exotic species increased with the burn treatment relative to controls $(p=0.002)$ (Fig. 13).

Target Species. In the L. ambiguus experiment, burning had a negative effect on mean Lessingia micradenia abundance $(p=0.016)$ (Fig. 14). In the B. hordeaceus experiment, L. ambiguus cover was significantly higher in burned quadrats than in controls $(p=0.024)$ (Fig. 15). Mean B. hordeaceus abundance greatly decreased in burned quadrats compared to controls $(p<0.001)$ (Fig. 16). 
Table 3. ANOVA $p$-values for $B$. hordeaceus experiment parameters. Significant $p$-values are $\underline{0.10}$ for pre-burn pairing and $\underline{\mathbf{0 . 0 5}}$ for treatment effect.

\section{Target Species}

L. ambiguus, \% Subplot Frequency

L. ambiguus, \% Cover$$
\underline{0.024} a
$$

B.hordeaceus, \% Subplot Frequency

L. micradenia, \% Subplot Frequency

0.523

$P$. erecta, \% Subplot Frequency

Grass Abundance

Native Perennial Grass Abundance,

$\%$ Subplot Frequency

$\begin{array}{ll}0.283 & 0.885\end{array}$

Native Annual Grass Abundance,

\% Subplot Frequency

$0.631 \quad \underline{\mathbf{0 . 0 3 4}}$

$\%$ Subplot Frequency

Total Grass Abundance,

\% Subplot Frequency

$\underline{0.063}$

$\underline{0.019}$

\section{Species Richness}

Native Species Richness, no. spp.

$\underline{0.054}$

0.693

Native Grass Richness, no. spp.

$\underline{0.051}$

0.859

Native Forb Richness, no. spp.

0.193

0.612

Exotic Species, no. spp.

0.840

$\underline{0.002}$

Exotic Grasses, no. spp.

1.000

0.297

Total Species, no. spp.

0.127

0.144

a Single measurement post-burn, not repeated 


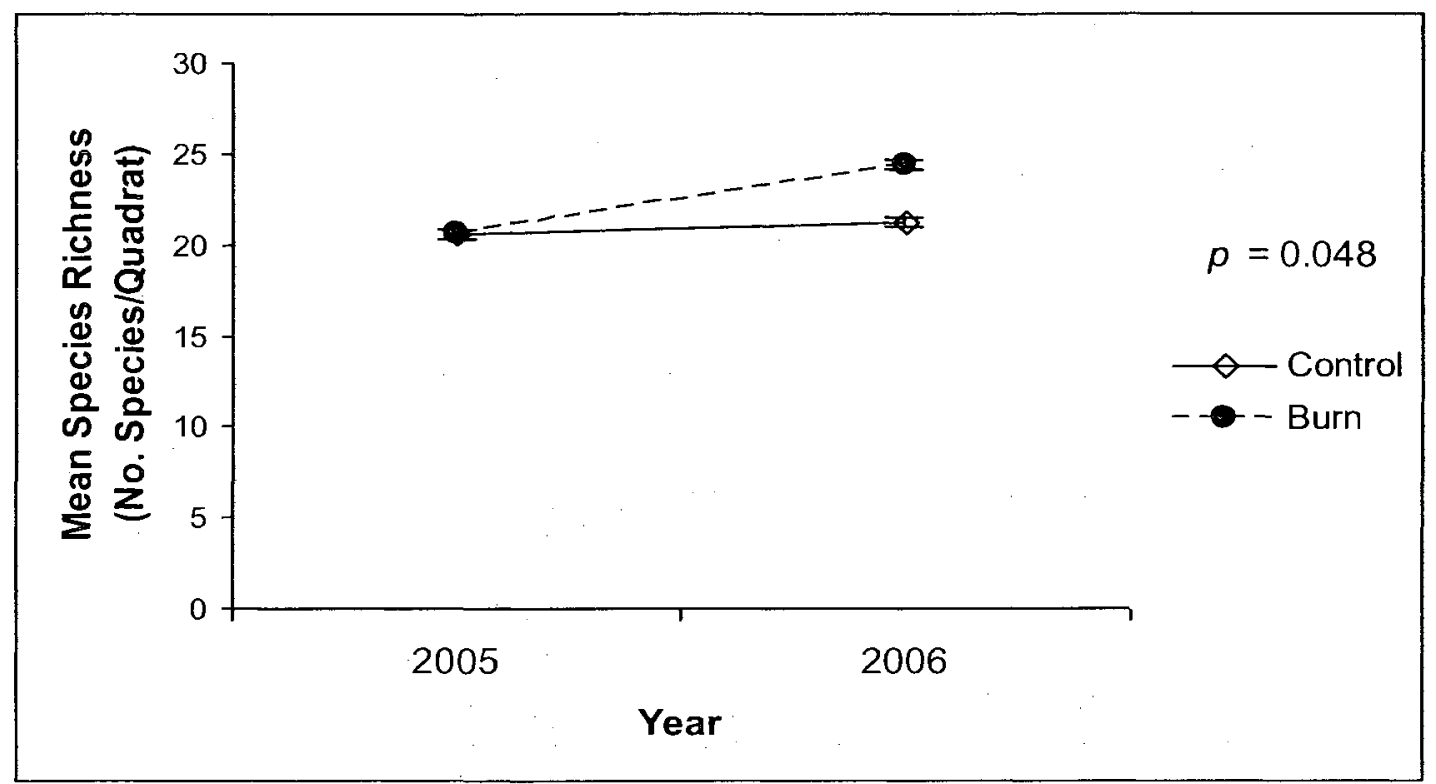

Figure 12. Effect of burning on total species number in L. ambiguus-rich experiment. Species number was enhanced in burned quadrats when compared to controls. Error bars represent $\pm \mathrm{SE}$.

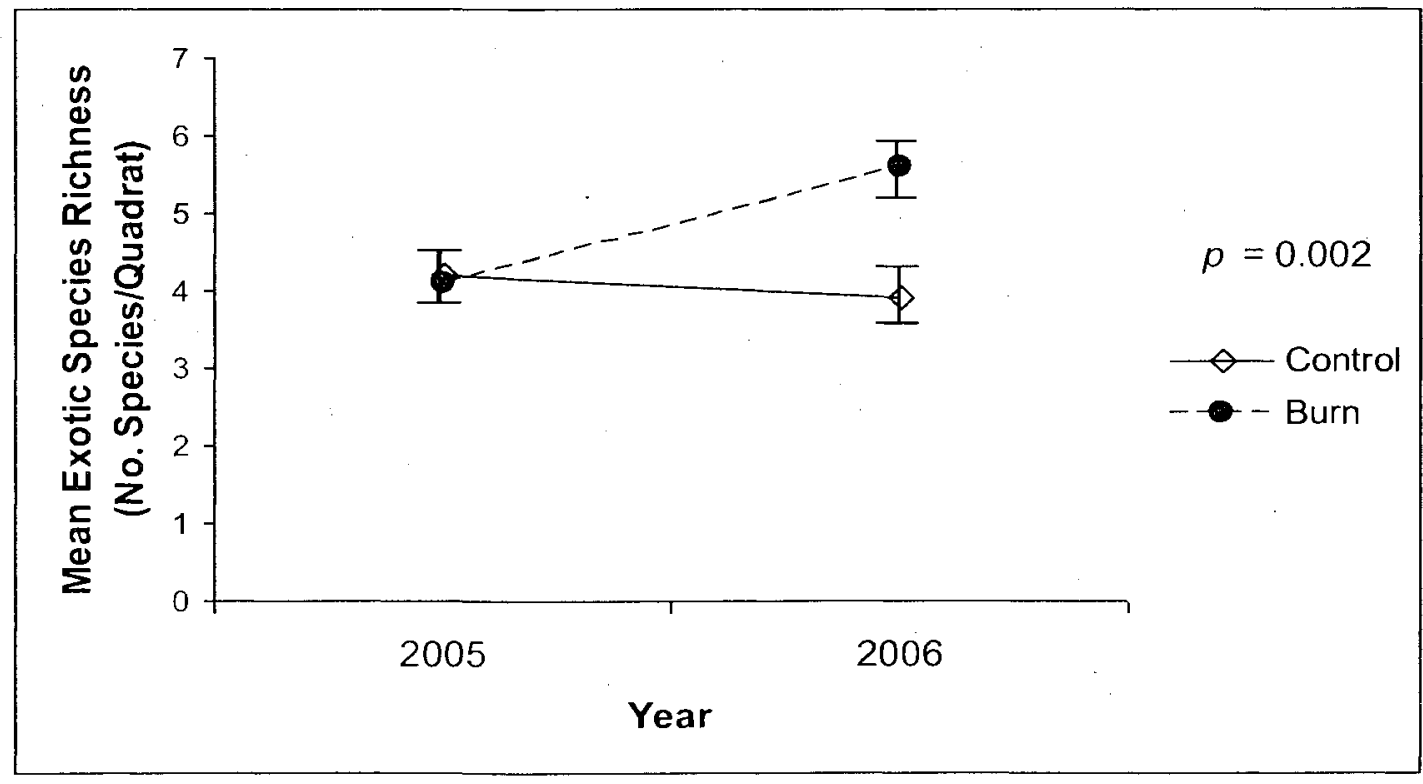

Figure 13. Effect of burning on exotic species richness in $B$. hordeaceus experiment. The number of exotic species increased in burned quadrats when compared to controls. Error bars represent $\pm \mathrm{SE}$. 


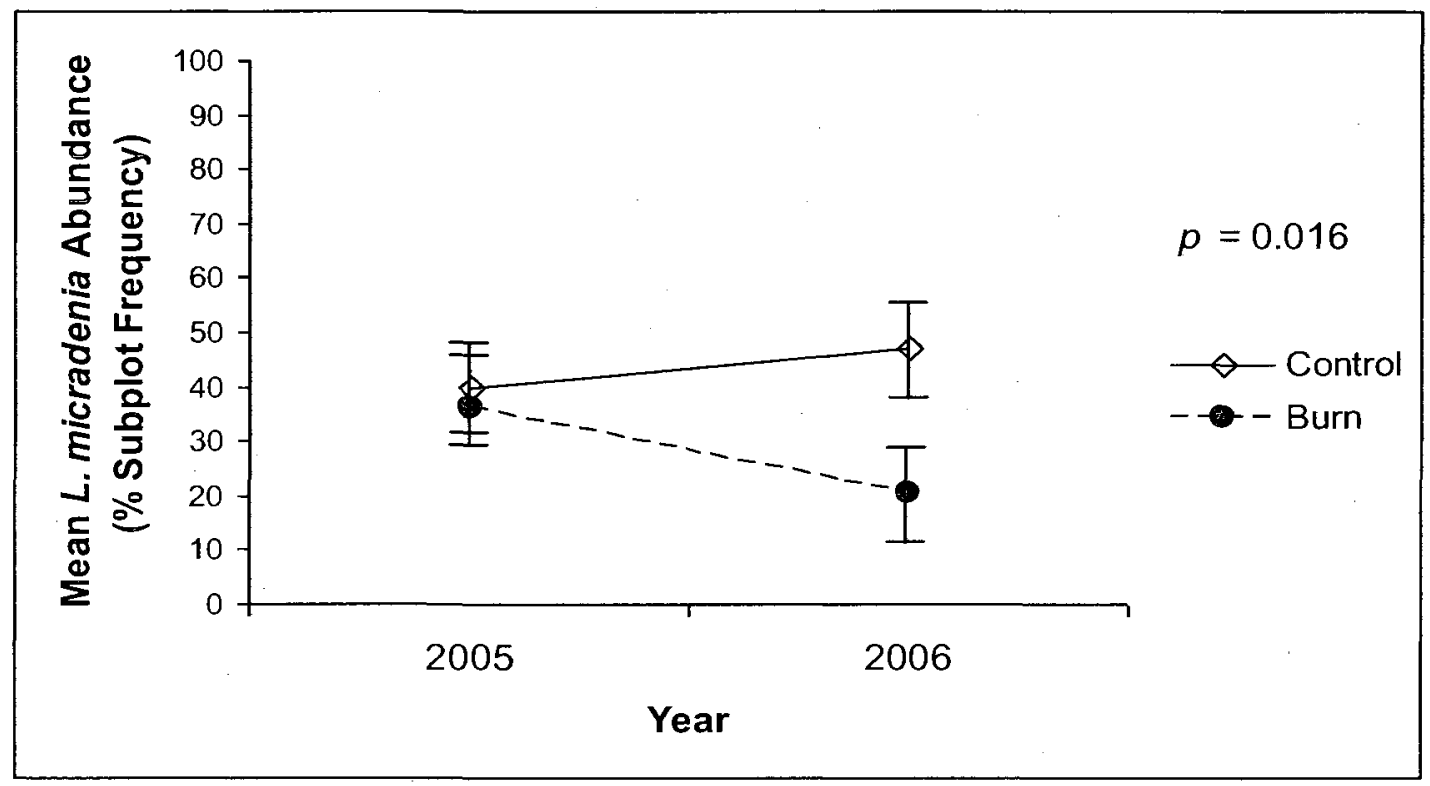

Figure 14. Effect of burning on L. micradenia var. glabrata abundance in L. ambiguus rich experiment. Lessingia micradenia was suppressed in burned quadrats when compared to controls. Error bars represent $\pm \mathrm{SE}$.

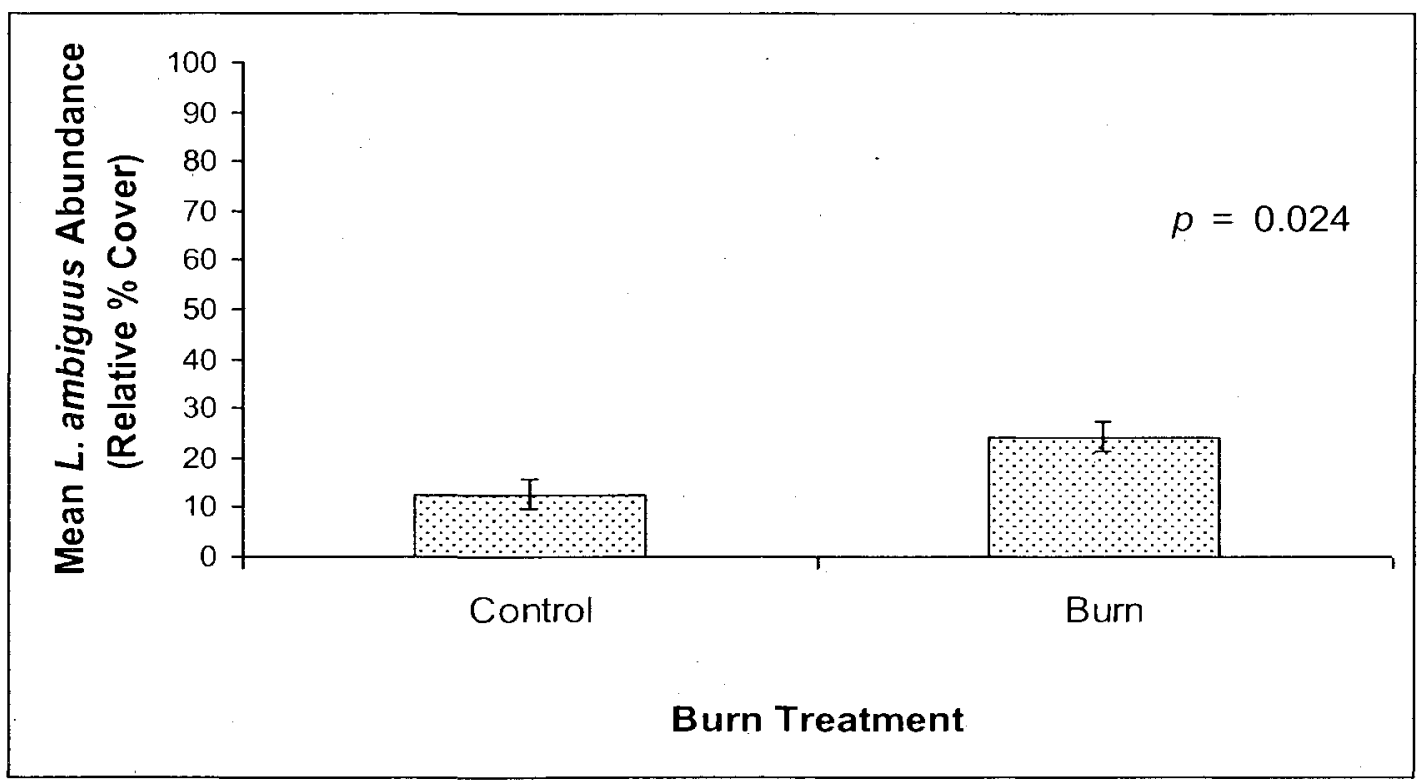

Figure 15. Effect of burning on L. ambiguus cover in 2006 in B. hordeaceus-invaded experiment. L. ambiguus cover increased in burned quadrats when compared to controls. Error bars represent $\pm \mathrm{SE}$. 


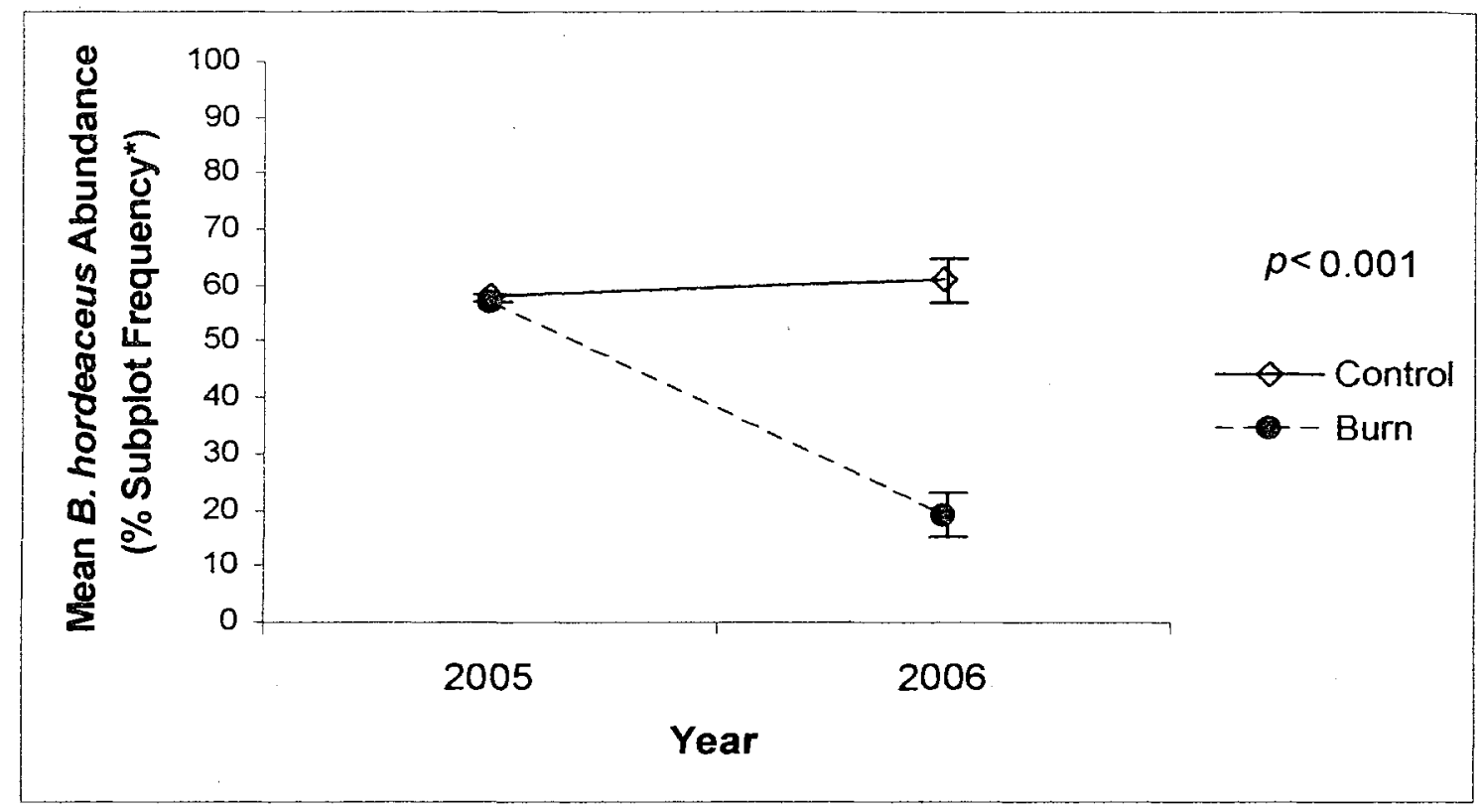

Figure 16. Effect of burning on $B$. hordeaceus abundance in $B$. hordeaceus invaded experiment. $B$. hordeaceus was suppressed in burned quadrats when compared to controls. *Frequency of subplots with $\geq 20$ plants. Error bars represent $\pm \mathrm{SE}$.

Grass Abundance. Burning had a negative impact on grass abundance. In L. ambiguus quadrats native annual grass abundance decreased in burned quadrats compared to controls. In the $B$. hordeaceus experiment, mean grass abundance significantly decreased in burned quadrats compared to controls for all grass groupings (except perennial grass, which had no significant effect) (Fig. 17-20). 


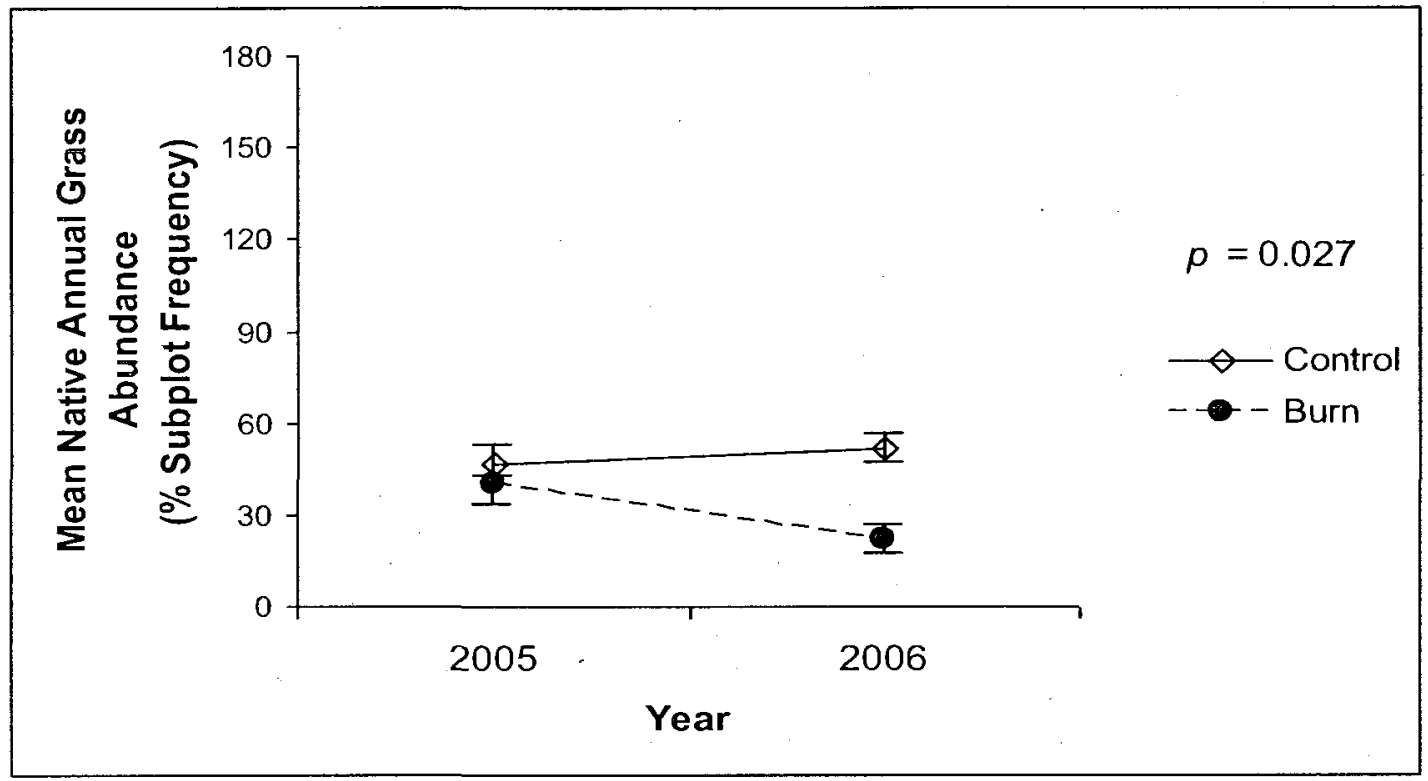

Figure 17. Effect of burning on native annual grass abundance in L. ambiguus-rich experiment. Error bars represent $\pm \mathrm{SE}$.

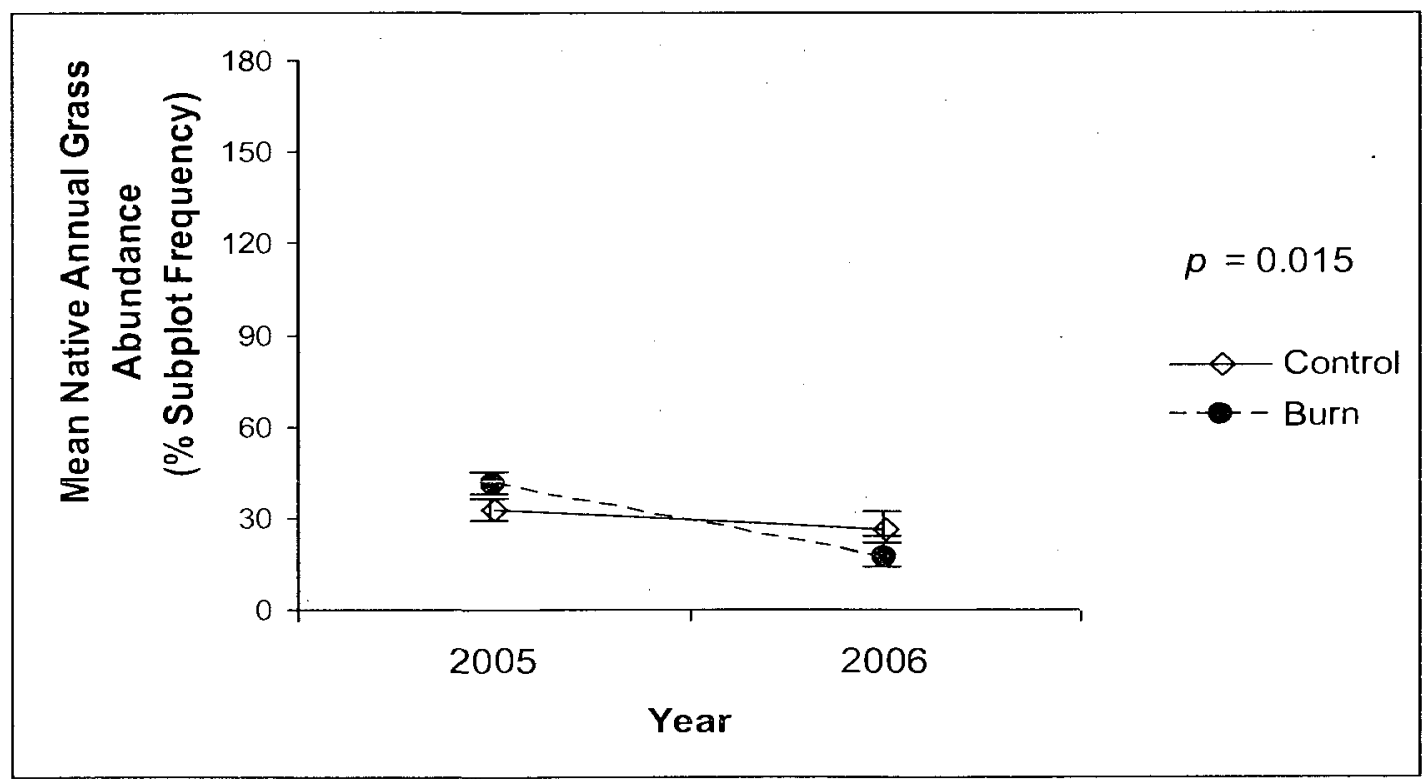

Figure 18. Effect of burning on native annual grass abundance in B. hordeaceus-invaded experiment. Error bars represent $\pm \mathrm{SE}$. 


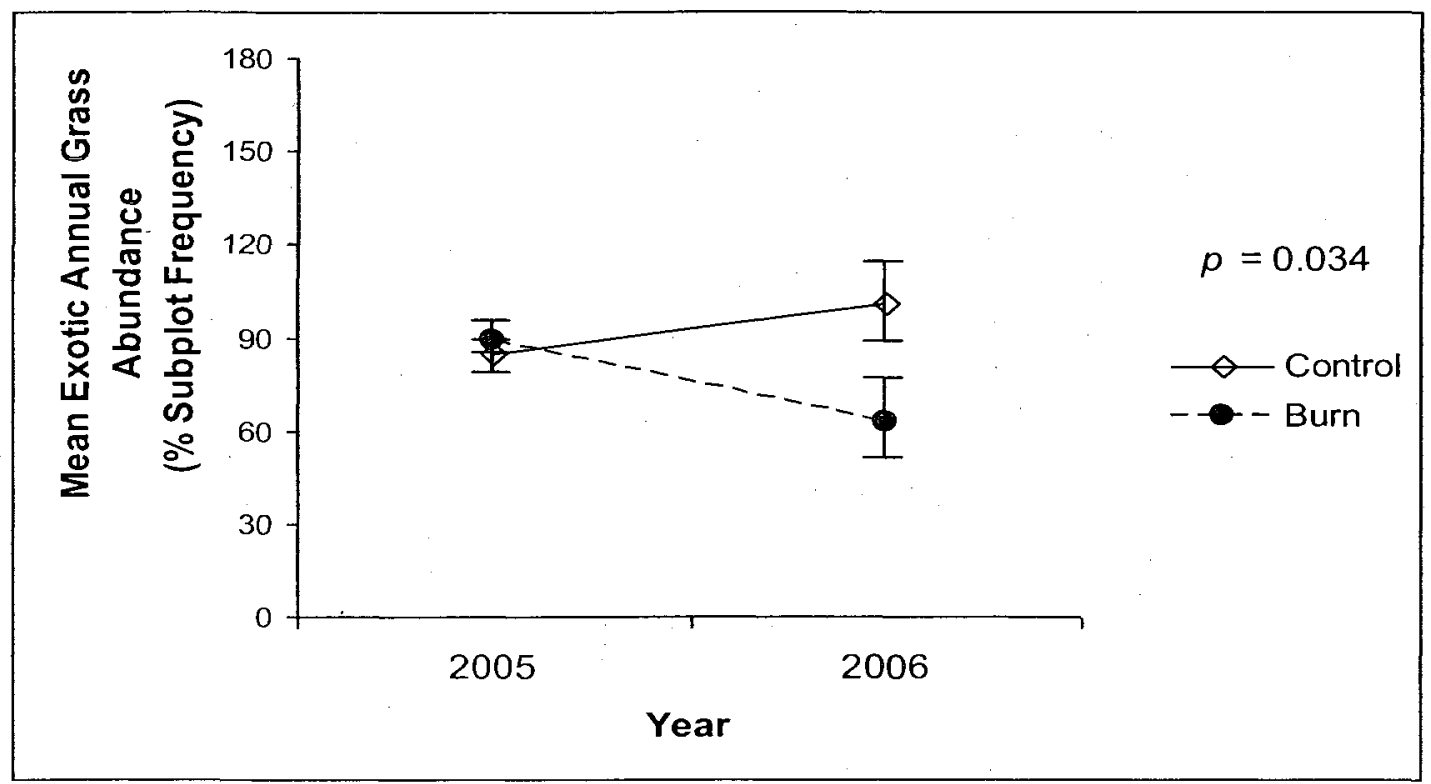

Figure 19. Mean exotic annual grass abundance in B. hordeaceus-invaded experiment. Error bars represent $\pm \mathrm{SE}$.

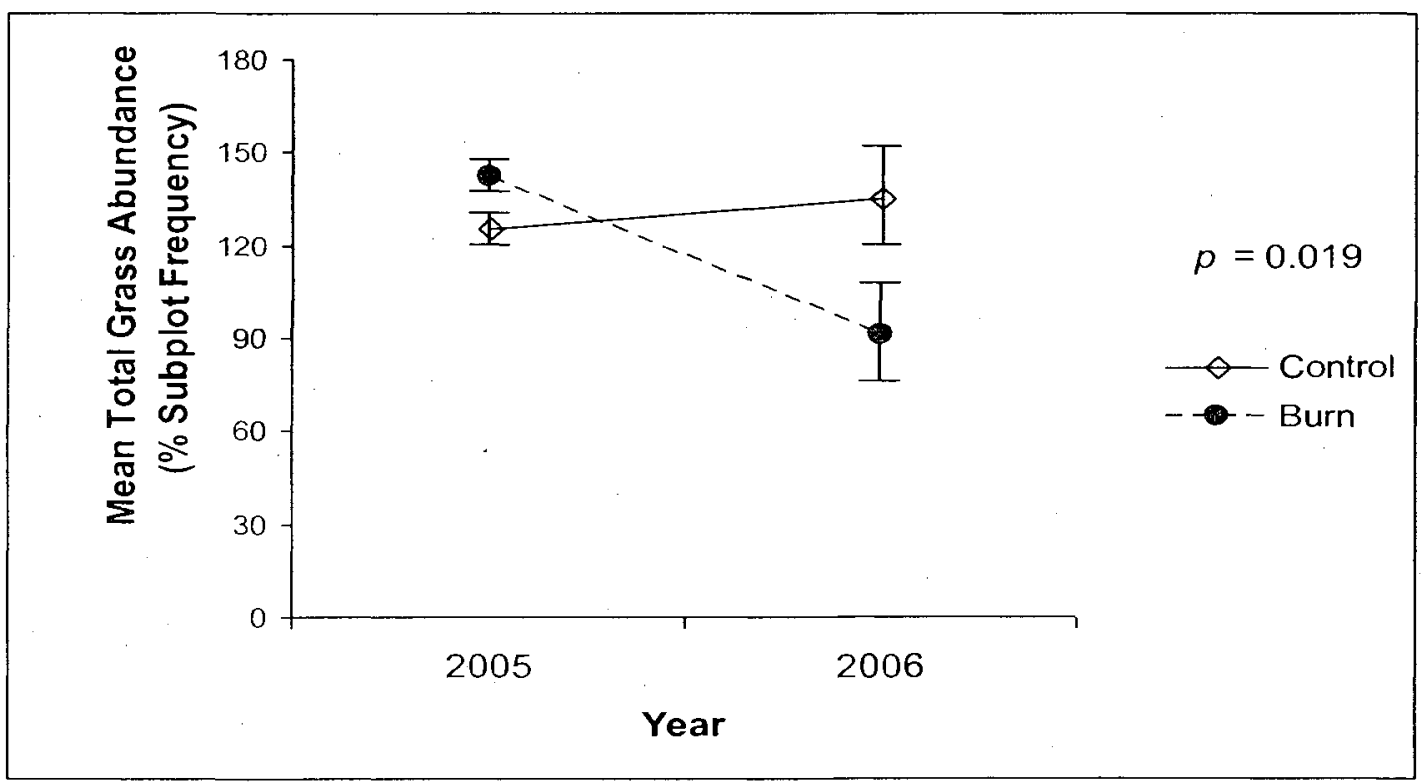

Figure 20. Mean total grass abundance in $B$. hordeaceus-invaded experiment. Error bars represent $\pm \mathrm{SE}$. 


\section{Burn Temperature Versus Vegetation Parameter Correlation and Follow-up}

Change in Plantago erecta abundance was the only parameter with an effect that was correlated with burn temperature. In the L. ambiguus-rich experiment, P. erecta abundance was positively correlated ( $r=0.686$ ) with burn temperature (Fig. 21A), but in the grass experiment, $P$. erecta abundance and burn temperature were negatively correlated ( $r=-0.855)$ (Fig. 21B). When data from both experiments were combined, P. erecta abundance and burn temperature were not correlated $(r=0.377)$.

In follow-up analyses of burned quadrats, there were no significant differences in mean initial $P$. erecta abundance, mean change in $P$. erecta abundance or mean burn temperature between the L. ambiguus experiment and the B. hordeaceus experiment that might explain the opposing correlations between change in $P$. erecta and burn temperature $(p>0.05)$ (Table 4$)$.

Table 4. Some parameters likely to explain opposing correlations were not significantly different.

\begin{tabular}{lc} 
Vegetation Parameter & $p$-Value \\
\hline Initial P. erecta Abundance, \% Subplot Frequency & 0.212 \\
Change in P. erecta Abundance, \% Subplot Frequency & 0.675 \\
Burn Temperature & 0.064
\end{tabular}




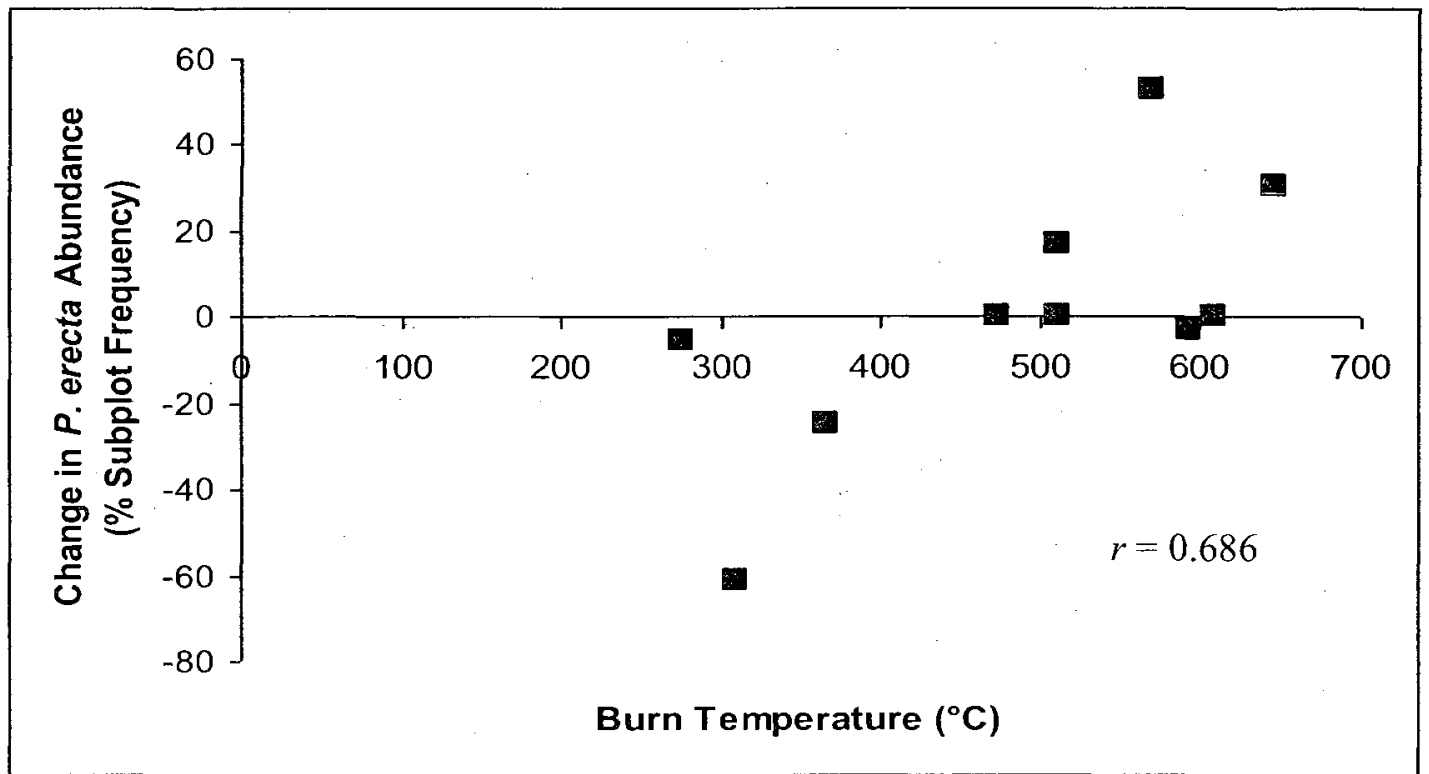

A. Leptosiphon ambiguus experiment.

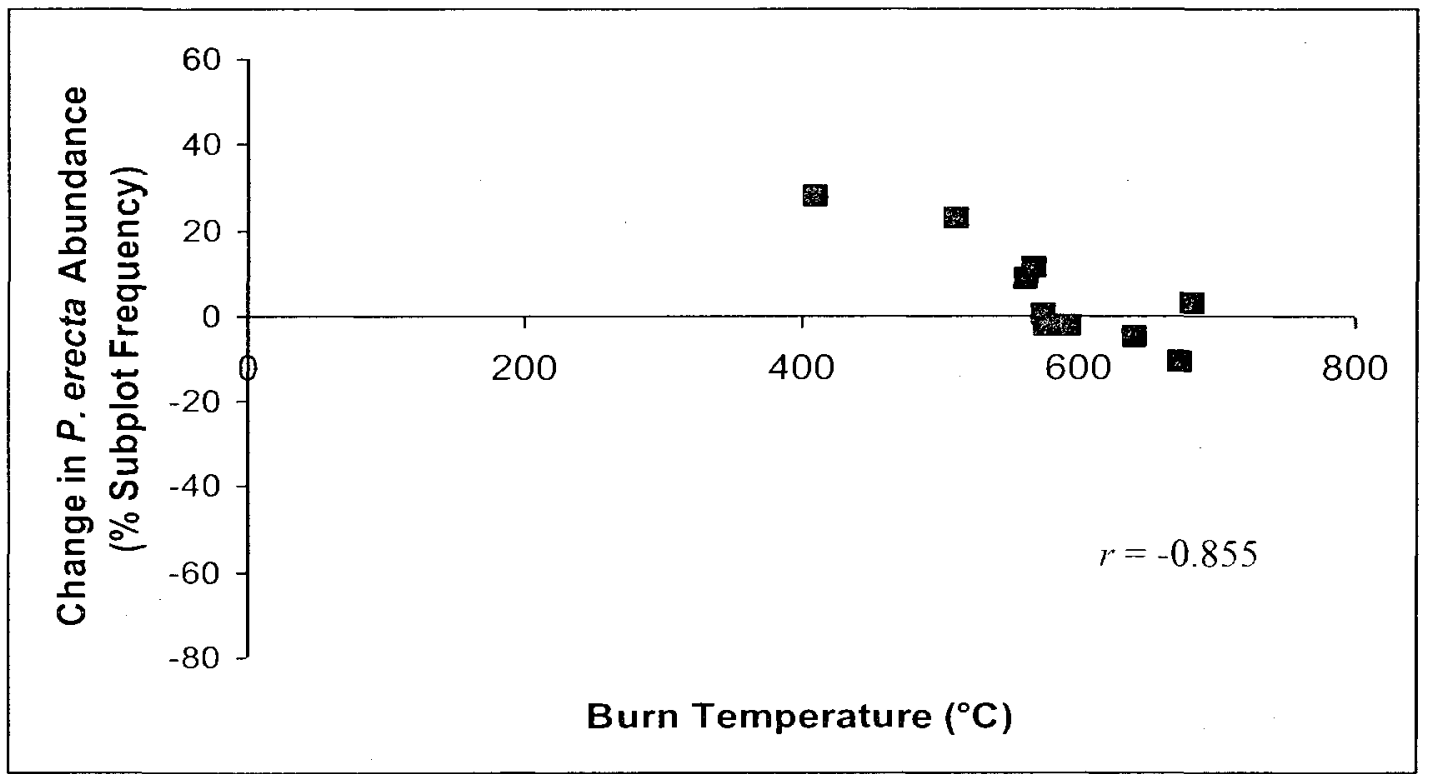

B. Bromus hordeaceus experiment.

Figure 21. Plantago erecta versus burn temperature correlation. A.) In L. ambiguusrich quadrats, there was an increase in $P$. erecta abundance with higher burn temperatures. B.) In B. hordeaceus-invaded quadrats, the opposite occurred; there was a decrease in $P$. erecta abundance with higher burn temperatures. 
There was no switch from a positive to negative correlation of burn temperature with change in $P$. erecta abundance $(|r|>0.6)$ based on temperature group divisions at $450,500,550$ and $570^{\circ} \mathrm{C}$ (Table 5). (Note that three L. ambiguus plots burned below $400^{\circ} \mathrm{C}$, no $B$. hordeaceus plots burned below $400^{\circ} \mathrm{C}$ and only one burned below $500^{\circ} \mathrm{C}$.)

Table 5. Correlation of change in $P$. erecta versus burn temperature at different burn temperatures.

\begin{tabular}{ccccc}
\hline Temperature $\left({ }^{\circ} \mathrm{C}\right)$ & $\begin{array}{c}\text { Number of plots } \\
\text { burning below } \\
\text { Temp. }\end{array}$ & $\begin{array}{c}\text { Correlation with } \\
\text { change in } P \text {. erecta } \\
(r \text { value })\end{array}$ & $\begin{array}{c}\text { Number of plots } \\
\text { burning above } \\
\text { Temp. }\end{array}$ & $\begin{array}{c}\text { Correlation with } \\
\text { change in } P \text {. erecta } \\
(r \text { value })\end{array}$ \\
\hline 450 & 4 & 0.532 & 16 & -0.192 \\
500 & 5 & -0.505 & 15 & -0.288 \\
550 & 8 & 0.633 & 12 & -0.271 \\
570 & 11 & 0.676 & 9 & 0.124
\end{tabular}

In the $L$. ambiguus quadrats $P$. erecta decreased with higher pre-burn native grass abundance $(r=-0.797)$ (Fig. 22). Burn temperature decreased with greater initial native perennial $(r=-0.780)$ and native annual grass $(r=-0.705)$ but increased with exotic annual grass $(r=0.626)$ (Fig. $23 \mathrm{~A}-\mathrm{C})$. In the B. hordeaceus experiment, burn temperature increased with abundance of all grasses combined $(r=0.701)$, but not with any individual group of grasses. (Fig. 23D). None of these measurements were correlated when data from the L. ambiguzs and B. hordeaceus experiments were combined. 


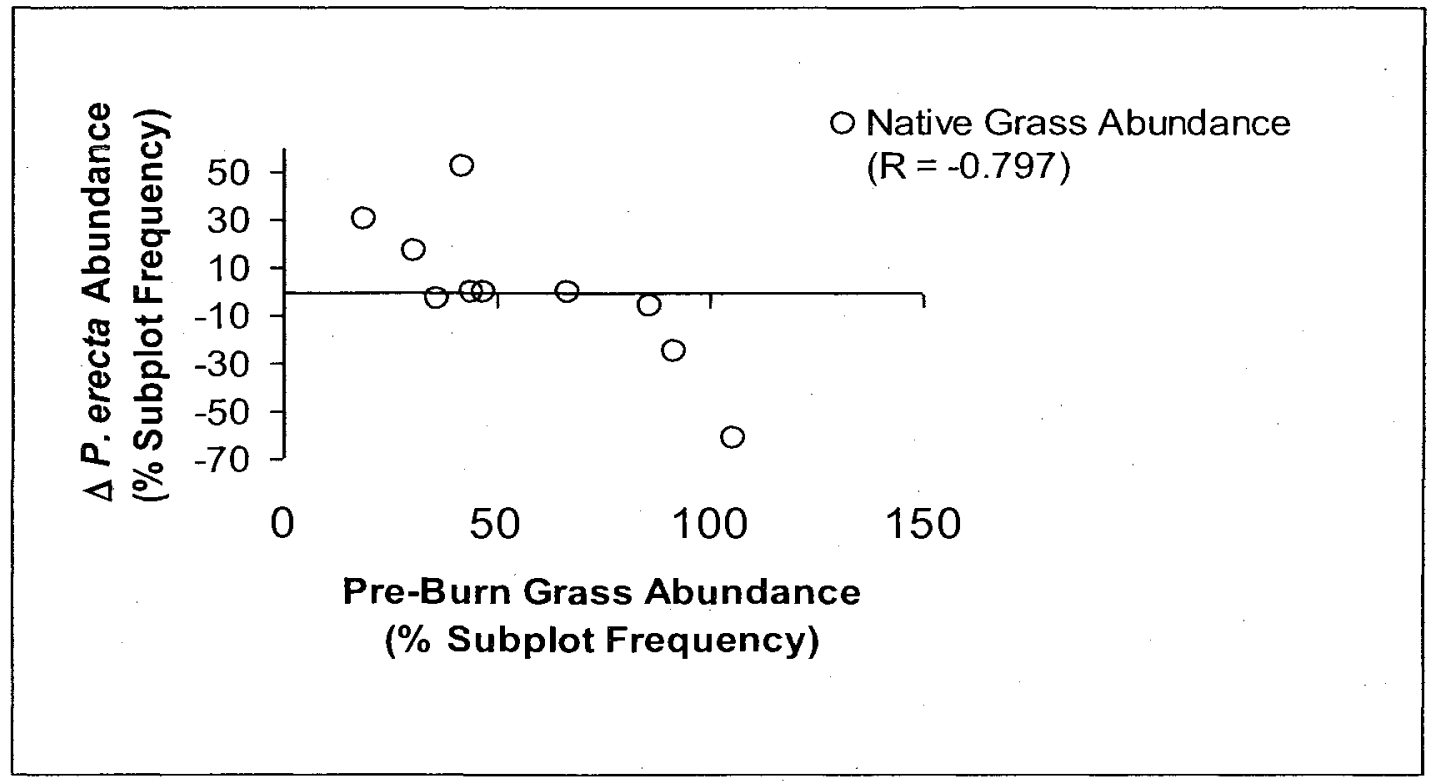

Figure 22. Change in $P$. erecta abundance in the L. ambiguus-rich experiment was correlated with pre-burn grass abundance of native grasses. 

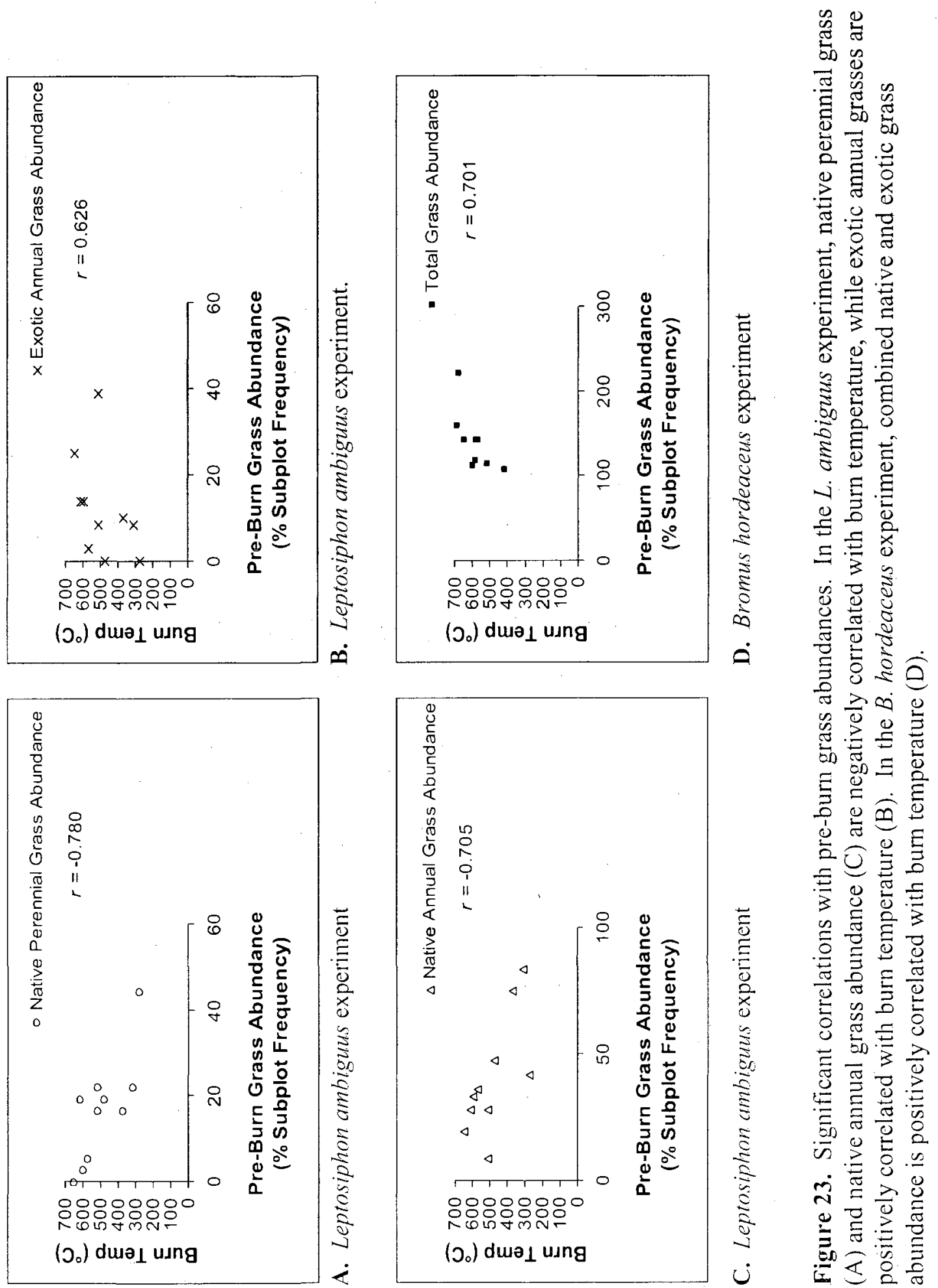


\section{Discussion}

\section{Overview of Vegetation Parameters}

Eight plants were found in 2006 but not in 2005 (Appendix A). For five of them [native forbs: Camissonia graciliflora (Hill suncup), and Claytonia spp. (Springbeauty), and exotic forb: Capsella bursa-pastoris (Shepherd's purse)], this may have been a sampling artifact because these species were all present early in the season but had shriveled and were indistinct later in the season (sampling was conducted earlier in the post-burn growing season than in the pre-burn season). Two of these species (both exotic forbs) should have been present late enough for the first year's sampling. They may have been stimulated by the fire; however, Erodium sp. (Filaree) occurred in both burned and control quadrats. It is likely that they were not found in the first year's sampling because they were uncommon in study quadrats [Erodium sp. occurred in four quadrats, and Medicago polymorpha (Bur clover) occurred in only one]. The one plant [exotic forb, Trifolium hirtum (Rose clover)] that occurred in 2006 in a burned quadrat, but not in 2005, may have been damaged by the fire. However, it occurred in only one quadrat the first year.

\section{Species Richness}

A beneficial outcome of burning is that species richness was enhanced in both experiments. The richness of all species increased in the Leptosiphon ambiguus experiment, although neither native nor exotic species numbers increased when analyzed separately. In the Bromus hordeaceus experiment, only exotic species richness increased. Noy-Meir (1995) reported that only grazed perennial grasslands consistently increased in 
species number. Vogl (1974), who reviewed several studies, also found that results of burning may be variable. Fire may either promote a mixture of annuals and enduring perennials or produce monocultures of fire-tolerant species. Seabloom et al. (2003) found that burning increased species diversity only when invaded grasslands were experimentally seeded. It is possible that the $B$. hordeaceus-invaded quadrats had limited seed banks of native species.

\section{Target Species}

Burning affected the two target species (L. ambiguus and B. hordeaceus) in ways that could be favorable from a management perspective. Leptosiphon ambiguus cover doubled and $B$. hordeaceus decreased to one-third its original value in the $B$. hordeaceusinvaded experiment. Because these effects occurred in the same experiment, L. ambiguus may have spread into areas invaded by $B$. hordeaceus, as postulated. Other possibilities are discussed below in the "Further Study" section.

A.negative result of the burn was that a rare plant, Lessingia micradenia var. glabrata, was suppressed by fifty percent. This is a concern, but the effect may not be as severe as it first appears. Even though L. micradenia suppression was anticipated (since it had not yet set and dropped its seeds, and it was still quite green), the plots were intentionally burned thoroughly in order to detect negative effects. Even so, L. micradenia was not eliminated from any plots. In a prescribed burn on a larger scale, areas that were not invaded could be skipped over, while invaded areas could be targeted. A fire also would flow naturally through the areas that had dense dry fuel (primarily areas 
invaded with annual non-native grasses) and might move around or incompletely burn green plants such as L. micradenia.

Both positive and negative results concur with Vogl (1974) who stated that native annuals are usually encouraged by fire when the burning occurs at the appropriate time. Fire provides exposed soil and full sun needed by most native annuals and provides heat that increases germination of others. In this study the burn occurred after L. ambiguus (and most of the native annuals) were senescent. B. hordeaceus was dry but had not dropped its seeds, and L. micradenia was still green. According to Vogl, some green annual plants, such as Eschscholzia californica (California poppy) can withstand "top removal" due to burning and produce seeds the following year. This phenomenon was not observed (nor looked for) in L. micradenia or other late-bloomers. Other latebloomers, including perennials, at this site included Eriogonum spp. (Buckwheat), Hemizonia congesta (Hayfield tarweed), and Calochortus argillosus (Clay mariposa lily).

\section{Grass Abundance}

Burning significantly decreased native annual grass abundance in both the L. ambiguus and B. hordeaceus experiments. It also decreased exotic annual, native annual, and total grass abundance in the $B$. hordeaceus experiment. Native perennials were the only grasses not significantly affected by burning in the $B$. hordeaceus experiment. Looking at all the grass abundance graphs together, they appear very similar (Fig. 17-20). Early summer burning reduced annual grasses. This was anticipated as most of them were senescent and dry yet had not dropped most of their seeds. 


\section{Change in Plantago erecta Correlated with Burn Temperature}

Although mean change in $P$. erecta abundance was not affected by burning in either experiment (the effect was marginally significant in L. ambiguus quadrats), change in $P$. erecta abundance was positively correlated with burn temperature in the L. ambiguus-rich experiment and negatively correlated with burn temperature in invaded quadrats. Initial $P$. erecta abundance did not account for the apparent difference in response. There are two possible biological explanations (initial differences in grass abundance and mycorrhizal communities) and two non-biological explanations (both involving burn temperature) for the opposing correlations. These are considered below.

Plantago erecta decreased in L. ambiguus quadrats with more native grass. It is possible that native grass abundance affected burn temperature. Burn temperature was lower in quadrats with more native grass and higher in quadrats with more exotic grass in the $L$. ambiguus experiment. Burn temperatures were also higher in quadrats with all grasses combined in the $B$. hordeaceus experiment.

It is logical that dry annual grass would burn at higher temperatures than perennial grass, which was still relatively moist. B. hordeaceus quadrats initially had more exotic annual grass than L. ambiguus. It would be expected that the exotic annual grass would drive the response (of increased burn temperature with more grass) in the $B$. hordeaceus experiment. However, native and exotic grasses appear to burn differently. It is not known why burn temperature would have been lower in L. ambiguus quadrats containing more native annual grasses. Initial native annual grass abundance represented a greater proportion of annual and total grass in the L. ambiguus quadrats than it did in 
the $B$. hordeaceus experiment. It is possible that the native grasses are more abundant in L. ambiguus quadrats that were burned later in the day (when dew had evaporated) or that their abundance indicates some unknown parameter (with their location within at the study site) and that this in turn affected the change in P. erecta abundance. The mycorrhizal fungal communities may have affected the change in $P$. erecta abundance with burn temperature. Plantago erecta has mycorrhizal associations (Chiariello et al. 1982) that may be altered by exotic grasses (Batten et al. 2006). Fire sometimes enhances, sometimes suppresses, and sometimes has no apparent effect on mycorrhizal communities (Bellgard et al. 1994).

Although mean burn temperatures were not significantly different between the two experiments, three $L$. ambiguus quadrats burned below $400^{\circ} \mathrm{C}$, but none of the B. hordeaceus quadrats did. Therefore, there is no data for how P. erecta abundance is affected at lower temperatures in the $B$. hordeaceus experiment.

It is also possible that the radiant temperature measured did not reflect ground temperature, since the highest temperatures are usually produced well above the ground at the apex of the flames or higher (Vogl 1974) (the radiant heat measurement was taken approximately $0.5 \mathrm{~m}$ above the ground). This would be especially likely if flame height was different for different types of grass. It is also possible that perennial grass burned longer, exposing the ground to high temperatures for a longer period.

To understand the relationship between the change in $P$. erecta abundance and burn temperature, further study under more tightly controlled conditions and using more replicates would be required. 


\section{Management Considerations}

Land managers must consider benefits and drawbacks of various management techniques and weigh them against taking no action at all. Benefits and risks to consider include feasibility, hazards, cost-effectiveness, and ecological management goals. Time of year, infrastructure (roads and fences already in place), proximity to man-made structures (homes), air quality, and community support can influence the balance. This study is primarily concerned with results to the environment, which are discussed in the conclusions. Each location must be considered independently.

Managers must consider effort and cost versus payback of different management methods. Rancho Cañada del Oro is fenced and therefore can be grazed by cattle, at a profit to land managers, when the land is leased to cattle owners. Cost may be prohibitive for grazing properties that are not fenced. Goats, which can be penned in small portable enclosures, require a goatherd where large predators are present. Burning can be an inexpensive management tool if performed outside the wildfire-danger season when minimal staff is needed (P. Congdon 2008, Santa Clara County Open Space Authority, San Jose, CA, personal communication).

Two drawbacks of burning as a management tool are the possibility of the fire spreading and the unpredictability of environmental conditions. It is not unusual for a scheduled fire to be cancelled due to fire danger or air quality issues. These two risks are minimized with burns performed before the surrounding environment dries out or after the first fall rains. The fact that most plants in serpentine grasslands mature and become senescent before the surrounding grasslands makes them candidates for earlier burns. 


\section{Further Study}

Further study could be done on serpentine endemic plants' response to fire. None of the study plots contained the rare plants Dudleya setchellii or Streptanthus albidus. Weiss (2007) found that fires moved around $D$. setchellii, a succulent, without damaging it. In a fire allowed to move naturally through the grassland, green $L$. micradenia might not be damaged either. Further study could determine whether or not fire would be detrimental to S. albidus. Like L. ambiguus, S. albidus begins flowering in early spring. If it senesces in time, it would be likely to sustain little damage and could even benefit from a burn.

Studies could be done to try to explain why L. ambiguus cover increased in the B. hordeaceus experiment. Possible explanations are that $L$. ambiguus' reproductive capacity increased, seed germination was enhanced and/or that it spread into areas previously occupied by other plants (Vogl 1974; Pendergrass 1999). These quadrats had a relatively high $L$. ambiguus abundance, so they would not have been seed-limited as in the study performed by Seabloom et al. (2003).

\section{Study Limitations}

In this study serpentine grassland samples were limited to two types: L. ambiguus patches that were invaded by $B$. hordeaceus, and those that were not. This method of sampling was chosen in order to reduce variance and to increase the ability to detect changes in rare plant $L$. ambiguus and its ability to spread into B. hordeaceus-invaded areas. All conclusions are restricted to areas with these conditions. Leptosiphon ambiguus-rich experiments contained many of the species found in the least-invaded 
zones in the serpentine grasslands and appeared to be fairly representative of these zones, except that $L$. ambiguus was more abundant in them. Bromus hordeaceus quadrats appeared to be fairly representative of mildly-invaded zones; once again L. ambiguus was over-represented. Although quadrats were not painstakingly paired for the other parameters, they were well-matched; only four out of 30 parameters were significantly different within pairs before the burn. So, it is not unreasonable that results would apply to the less-invaded serpentine grasslands in general.

Parts of the grassland that were notably missing were patches of dense perennial grasses (especially Nasella pulchra) and serpentine fringes invaded by Avena fatua or Lolium multiflorum. Leptosiphon ambiguus was not found in areas dense with either of these invasive grasses, but was found (the second year only) in the perennial grassland area. Previous studies indicate that $N$. pulchra responds favorably to burning but give no information about how L. ambiguus responds in N. pulchra-dominated grasslands.

Most abundance data were limited to frequency of subplots per quadrat. The assumption is that the number of subplots containing a species is indicative of the abundance in the entire quadrat. Percent cover, which is a more accurate and more common measure of abundance, was only collected for post-burn L. ambiguus. Percent subplot frequency was chosen in this study due to unfamiliarity with a number of species, difficulty in estimating $L$. ambiguus cover, and choosing to use a consistent measure of abundance among parameters that would (in addition) remain constant through most of the growing season. 
Conclusions are limited to one site and to one year post-burn only. Conclusions can not be applied to sites with different species composition or soil type. Pendergrass et al. (1999) and Weiss et al. (2007) found that results may not be long-lasting. Increases in native species abundance and diversity and decreases in invasive exotics persist in some cases, but not in others.

\section{Conclusions}

Early summer burning appears to be an effective management tool in serpentine grasslands at Rancho Cañada del Oro even where grazing has occurred on a regular basis. There were three main benefits and one drawback as a result of burning at Rancho Cañada del Oro, a preserve that has been grazed for 100 years. The question is whether increased species richness, the reduction of an invasive grass, and an increase in abundance of one rare plant outweigh the reduction in abundance of another rare plant. Given $B$. hordeaceus' adaptation to serpentine grasslands (especially on small patches) (Harrison et al. 2001), benefits do appear to outweigh the one disadvantage. The best approach may be to combine grazing and burning. Collins (1992) found that biodiversity increased in grasslands with variable prescribed burning regimes. Grazing can be performed on a regular basis; the best burning regime can be investigated and carried out when fire hazard and air quality conditions permit. 


\section{Implications for Practice}

- Refined pairing allowed treatment differences to be found that would otherwise have been lost due to variance in data.

- Results from this controlled study, with before and after data, showed similar benefits to those documented in wildfire studies.

- One rare endemic benefited from the burn and another was suppressed.

- Burn boxes provided a relatively safe way of testing the effects of prescribed fire on target species. 


\section{LITERATURE CITED}

Aerts, R. and F. Berendse 1988. The effect of increased nutrient availability on vegetation dynamics in wet heathlands. Vegetatio 76:63-69.

Barry, S. J. 1998. Managing the Sacramento Valley vernal pool landscape to sustain the native flora. Pages 236-240 in C.W. Witham, and E. T. Bauder, D. Belk, W. R. Ferren Jr., and R. Ornduff, editors. Ecology, conservation, and management of vernal pool ecosystems- proceedings from a 1996 conference. California Native Plant Society, Sacramento.

Batten, K. M., K. M. Scow, K. F. Davies, and S.P. Harrison 2006. Two invasive plants alter soil microbial community composition in serpentine grasslands. Biological Invasions 8:217-230.

Bell, C. D., and R. W. Patterson 2000. Molecular phylogeny and biogeography of Linanthus (Polemoniaceae). American Journal of Botany. 87:1857-1870.

Bellgard, S. E., R. J. Whelan, and R. M. Muston 1994. The impact of wildfire on vesiculararbuscular mycorrhizal fungi and their potential to influence the re-establishment of post-fire plant communities. Mycorrhiza 4:139-146.

Bobbink, R., and J. G. Roelofs 1995. Nitrogen critical loads for natural and semi-natural ecosystems: The empirical approach. Water Air and Soil Pollution 85:2413-2418.

Bowcutt, F. 1999. A floristic study of Sugarloaf Ridge State Park, Sonoma County, California. Aliso 18:19-34.

Calflora: Information on California plants for education, research and conservation, 2009. Berkeley, CA: The Calflora Database (a non-profit organization). URL http:/www.calflora.org/ [accessed 18 February 2009].

California Invasive Plant Council (CalIPC), 2009. Berkeley, CA: Invasive plant profile. http://www.cal-ipc.org/ip/management/plant profiles/index.php [accessed 28 February 2009].

California Native Plant Society (CNPS) 2009. Inventory of rare and endangered plants (online edition, v7-09a). California Native Plant Society. Sacramento, CA. URL http://www.cnps.org/inventory [accessed on 18 February 2009].

Chiariello, N., J. C. Hickman, and H. A. Mooney 1982. Endomycorrhizal role for interspecific transfer of phosphorus in a community of annual plants. Science 217:941-943. 
Cilimburg, A. C., and K. C. Short 2005. Forest fire in the US Northern Rockies: A primer. URL http://www.northernrockiesfire.org/effects/soilindi.htm [accessed 27 February 2009].

Collins, S. 1992. Fire frequency and community heterogeneity in tallgrass prairie vegetation. Ecology 73:2001-2006.

Collins, S. 1998. Modulation of diversity by grazing and mowing in native tallgrass prairie. Science 280:746-747.

DiTomaso, J. M., Kyser, M. S. Hastings 1999. Prescribed burning for control of yellow starthistle (Centaurea solstitialis) and enhanced native plant diversity. Weed Science 47:233-242.

Goodwillie, C. 1999. Wind pollination and reproductive assurance in Linanthus parviflorus (Polemoniaceae), a self-incompatible annual. American Journal of Botany 86:948-954.

Gundale, M. J. 2005. Nitrogen cycling and spatial heterogeneity following fire and restoration treatments in the ponderosa pine/Douglas-fir ecosystem. Dissertation. University of Montana, Missoula.

Harrison, S. K. Rice; and J. Maron 2001. Habitat patchiness promotes invasion by alien grasses on serpentine soil. Biological Conservation 100:45-53.

Harrison, S., B. D. Inouye, and H. D. Safford 2003. Ecological heterogeneity in the effects of grazing and fire on grassland diversity. Conservation Biology 17:837845 .

Heady 1977, H. F. 1977. Valley grassland. Pages 491-514 in M. G. Barbour and J. Major, editors. Terrestrial vegetation of California. California Native Plant Society, Sacramento.

Hickman, J. C. editor. 1993. The Jepson Manual, Higher Plants of California. University of California Press, Berkeley.

Hickman, J. C. editor 2009. The Jepson Manual, Higher Plants of California, (online edition). Jepson flora project: Jepson interchange for California floristics. The Jepson Herbarium Berkeley, CA. URL

http://ucjeps.berkeley.edu/interchange/1_treat_indexes.html [accessed 19 February 2009].

California Native Plant Society (CNPS) 2009. Inventory of rare and endangered plants (online edition, v7-09a). California Native Plant Society. Sacramento, CA. URL http://www.enps.org/inventory [accessed on 18 February 2009]. 
Huenneke, L. F., S. P. Hamburg, R. Koide, H. A. Mooney, and P. M. Vitousek 1990. Effects of soil resources on plant invasion and community structure in Californian USA serpentine grassland. Ecology 71:478-491.

Kruckeberg, A. R. 1984. California serpentines: Flora, vegetation, geology, soils and management problems. University of California Press, Berkeley.

MacArthur, R. H. and E. O. Wilson. 1967. The theory of island biogeography. Princeton University Press, Princeton.

McNaughton, S. J. 1968. Structure and Function in California grasslands. Ecology 49:962-972.

Menke, J. W. 1989. Grazing and fire management for native perennial grass restoration in California grasslands. Fremontia 20:22-25.

Meyer, M. D., and P. M. Schiffman 1999. Fire season and mulch reduction in a California grassland: A comparison of restoration strategies. Madroño 46:25-37.

Mooney, H. A., S. P. Hamburg, and J. A. Drake 1986. The invasion of plants and animals into California. Pages 250-272 in H. A. Mooney and J. A. Drake, editors. Ecology of biological invasions of North America and Europe. Springer Verlag, Berlin.

Murphy, D. D., and P. R. Ehrlich 1989. Conservation biology of California's remnant native grasslands. Pages 201-211 in Huenneke, L. F. and Mooney, H., editors. Grassland structure and function: California annual grasslands. Kluwer Academic Publishers, Dordrecht, the Netherlands.

Natural Resources Conservation Service, National Water and Climate Center, 1971-2000. ftp://ftp.wcc.nrcs.usda.gov/support/climate/taps/ca/06085.txt [accessed 26 February 2009].

Neary, D. G., C. C. Klopatek, L. F. DeBano, and P. F. Ffolliott 1999. Fire effects on belowground sustainability: A review and synthesis. Forest Ecology and Management 122:51-71.

Noy-Meir, I 1995. Interactive effects of fire and grazing on structure and diversity of Mediterranean grasslands. Journal of Vegetation Science 6:701-710.

Patterson, R. 1977. A revision of Linanthus section siphonella Polemoniaceae. Madroño $24: 36-48$.

Parsons, D. J. and T. J. Stohlgren 1989. Effects of varying fire regimes on annual grasslands in the southern Sierra Nevada of California. Madrono 36:154-168. 
Pendergrass, K. L., P. M. Miller, J. B. Kauffman, and T. N. Kaye 1999. The role of prescribed burning in maintenance of an endangered plant species, Lomatium bradshawii. Ecological Applications 9:1420-1429.

Porter, J. M. 1998. Nomenclature changes in Polemoniaceae. Aliso 17:83-85.

Porter, J. M., and L. A. Johnson 2000. A phylogenetic classification of Polemoniaceae. Aliso 19:55-91.

Power, S. A., M. R. Ashmore, D. A. Cousins, and N. Ainsworth 1995. Lon term effects of enhanced nitrogen deposition on a lowland dry heath in southern Britain. Water air and soil pollution 85:1701-1706.

Safford, H. D., Viers, J. H. and Harrison, S. P. 2005 Serpentine endemism in the California flora: A database of serpentine affinity. Madroño, 52:222-257.

Schmidtt, J. M. 1981. Pollinator foraging and evolution in flowering plant populations. Dissertation. Stanford University, Stanford.

Seabloom, Eric W., E. T. Borer, V. L. Boucher, R. S. Burton, K. L. Cottingham, L. Goldwasser, W. Gram, B. E. Kendall, and M. Fiorenza 2003. Competition, seed limitation, disturbance, and reestablishment of California native annual forbs. Ecological Applications 13:575-592.

Thomsen, C., W. A. Williams, M. Vayssieres, F. L. Bell, M. R. George 1993. Controlled grazing on annual grasslands decreases yellow starthistle. California agriculture 47:36-40.

U.S. Fish and Wildlife Service 1998. Recovery Plan for Serpentine Soil Species of the San Francisco Bay Area. Portland, Oregon.

U.S. Forest Service 2005. Wildland fire in ecosystems effects of fire on soil and water. http://www.fs.fed.us/rm/pubs/rmrs_gtr042_4.pdf [accessed Feb 27 2009].

United States Department of Agriculture 1974. Soil survey of the eastern Santa Clara area, California. USGPO, Washington.

Vogl, R. J. 1974. Effects of fire on grasslands. Pages 139-194 in T. T. Kozlowski and E. E. Ahlgren, editors. Fire and ecosystems. Academic Press, New York.

Weiss, S. 1999. Cars, cows, and checkerspot butterflies: Nitrogen-deposition and management of nutrient-poor grasslands for a threatened species. Conservation Biology 13:1476-1486. 
Weiss, S. B., and D. H. Wright 2005. Serpentine Vegetation Management Project Report (to US Fish and Wildlife Service). Creekside Center for Earth Observation. Menlo Park, CA. URL

http://www.creeksidescience.com/files/weiss_et_al_2005_usfws_serpveg.pdf [accessed 20 February 2009].

Weiss, S. B., D. H. Wright, and C. Niederer 2007. Serpentine vegetation management project final report (to US Fish and Wildlife Service). Creekside Center for Earth Observation. Menlo Park, CA. URL http://www.creeksidescience.com/files/weiss_et_al_2007_usfws_serpveg.pdf [accessed 20 February, 2009].

Whelan, R. 1995. The ecology of fire. Cambridge University Press, Cambridge. 


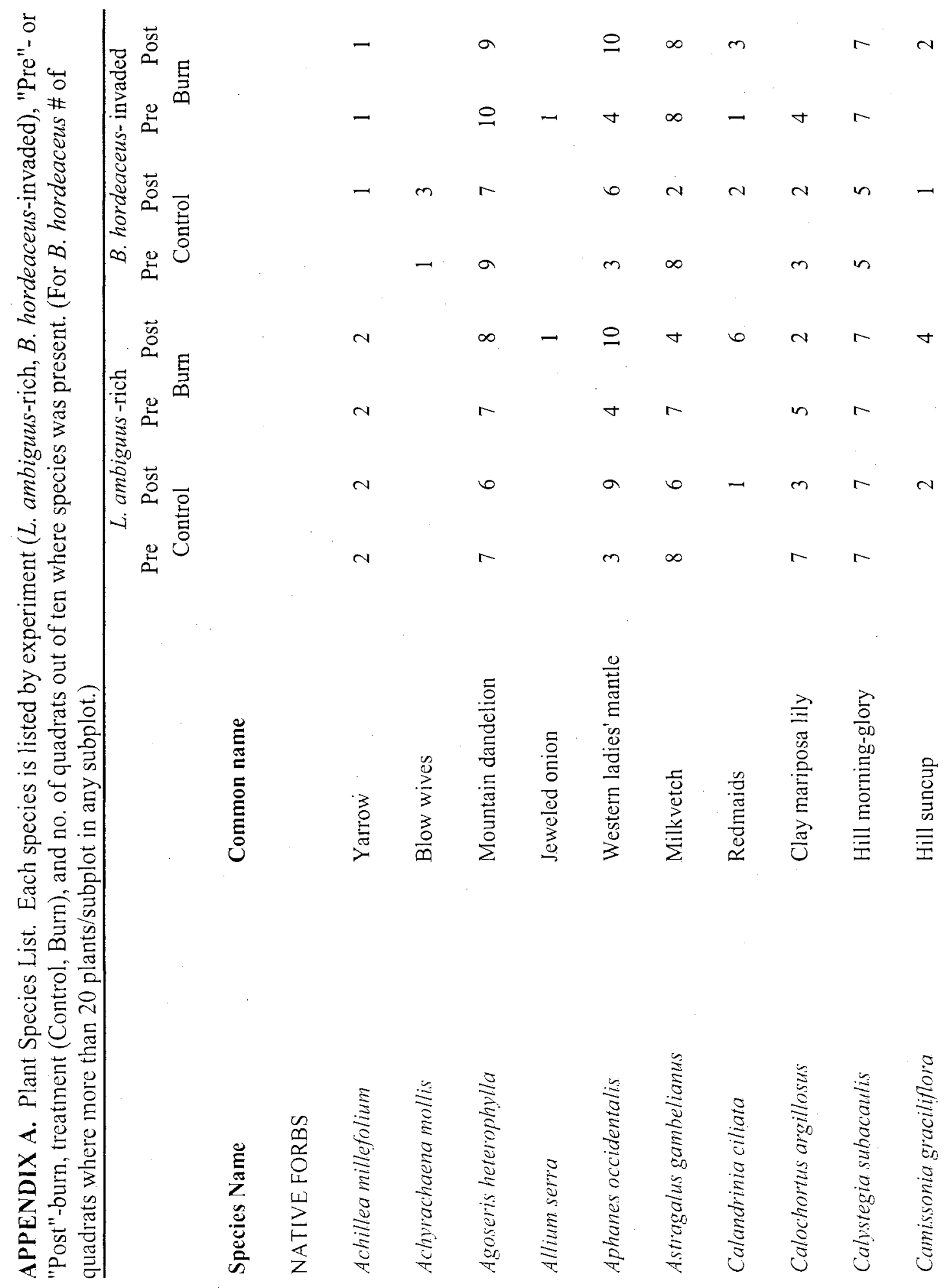



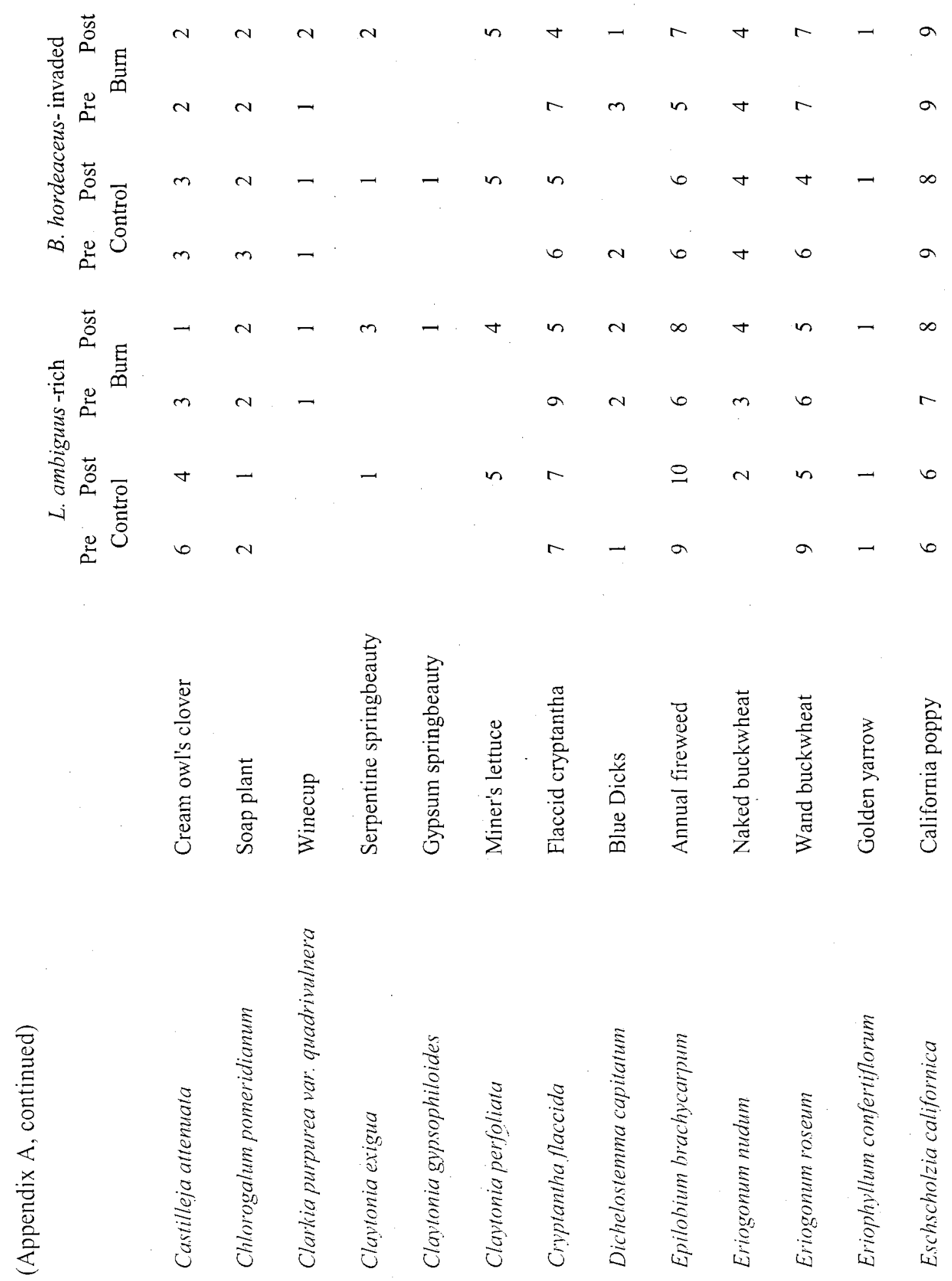

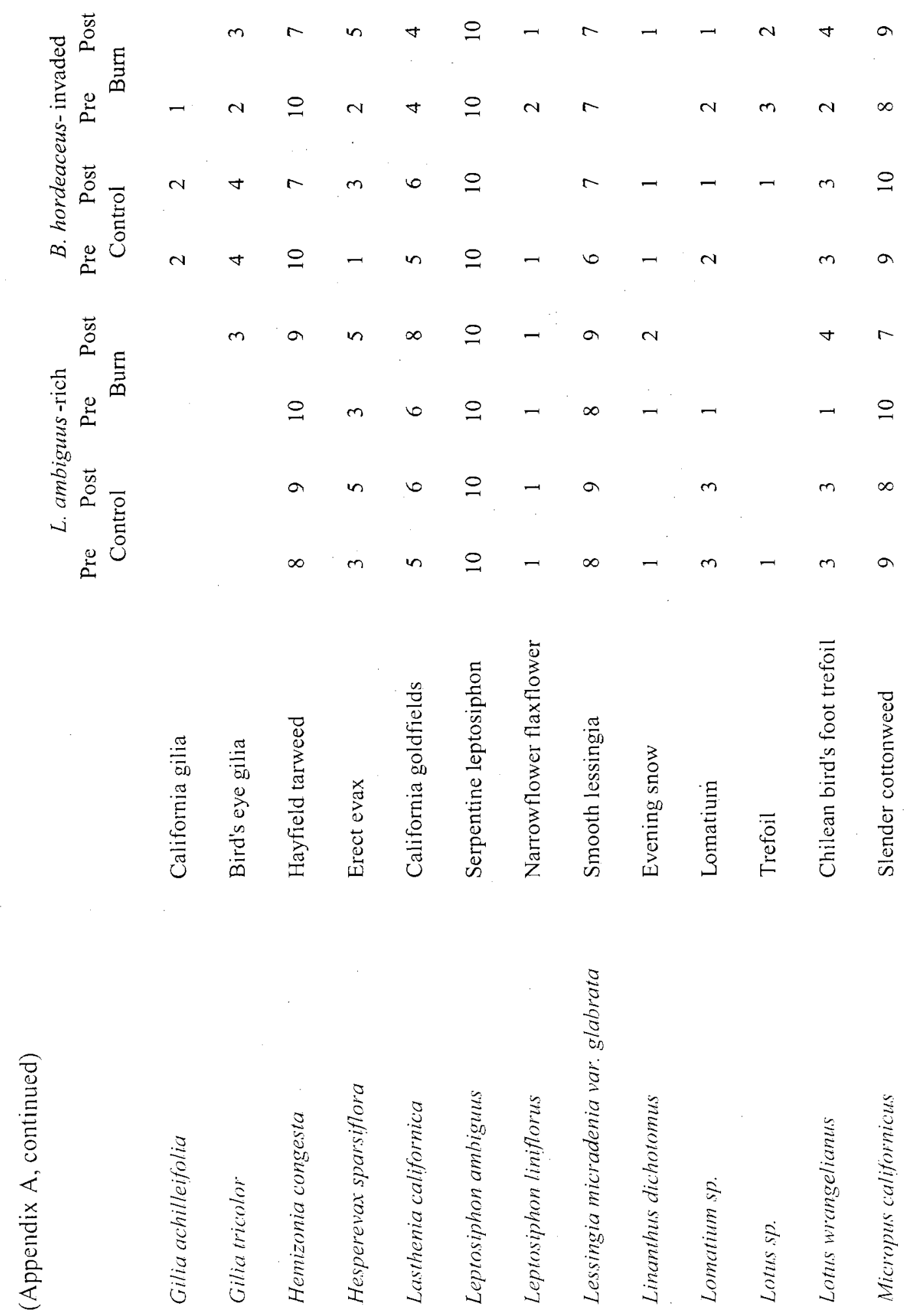

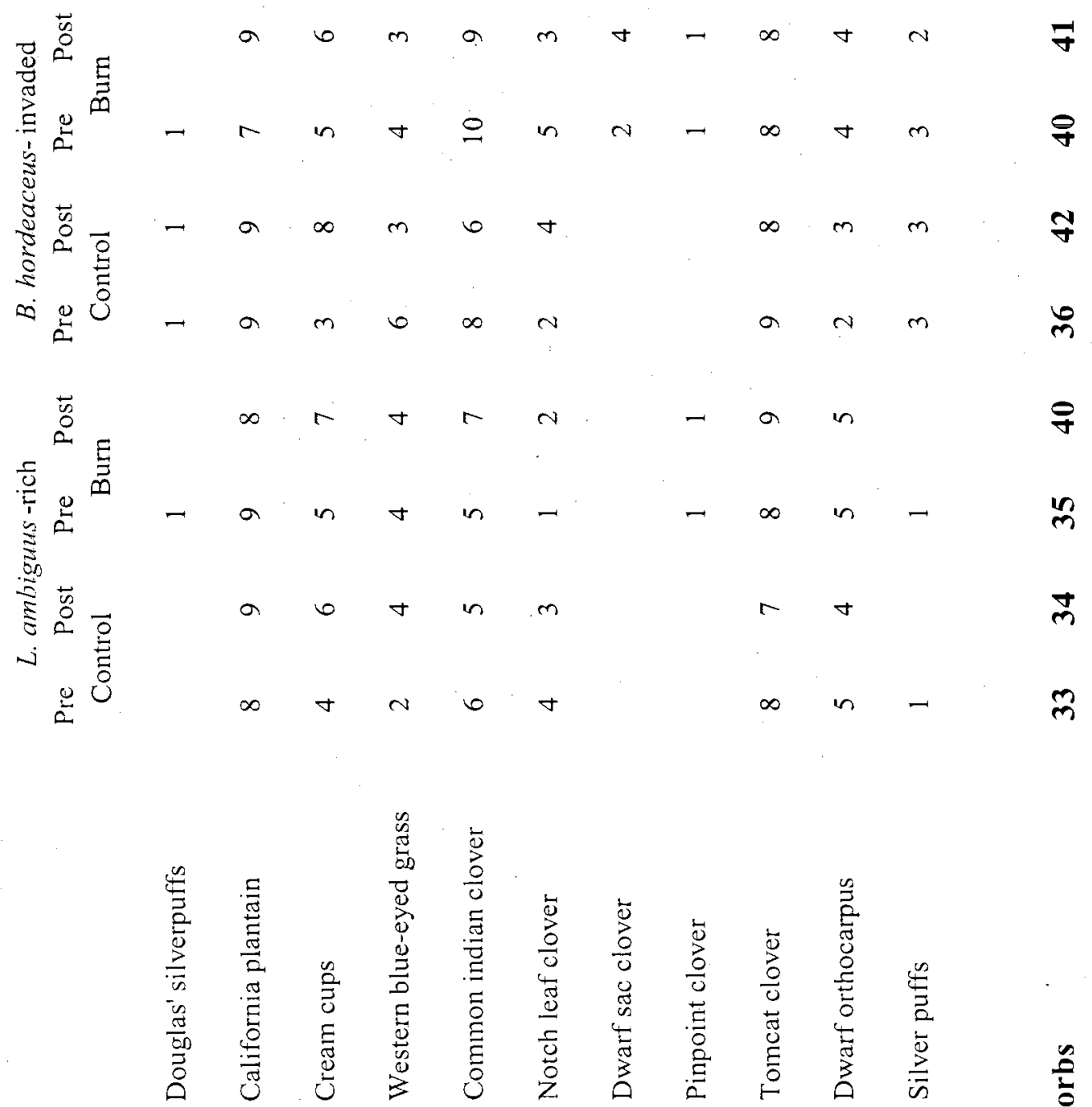

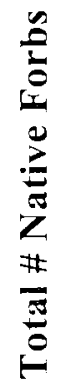

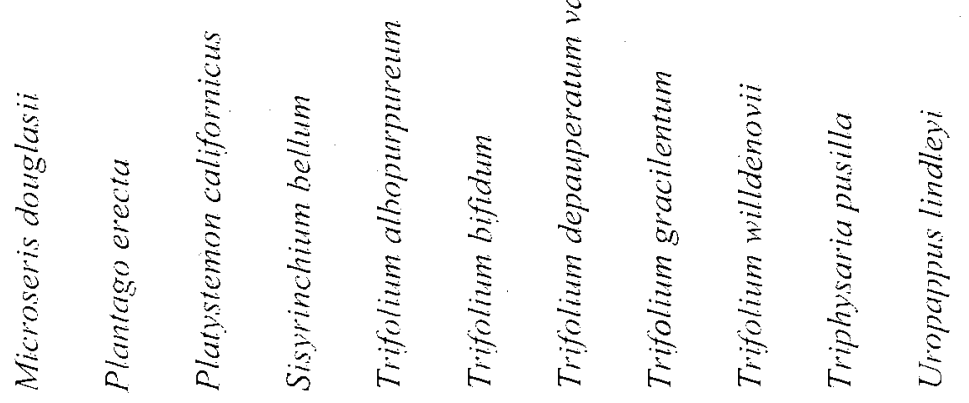



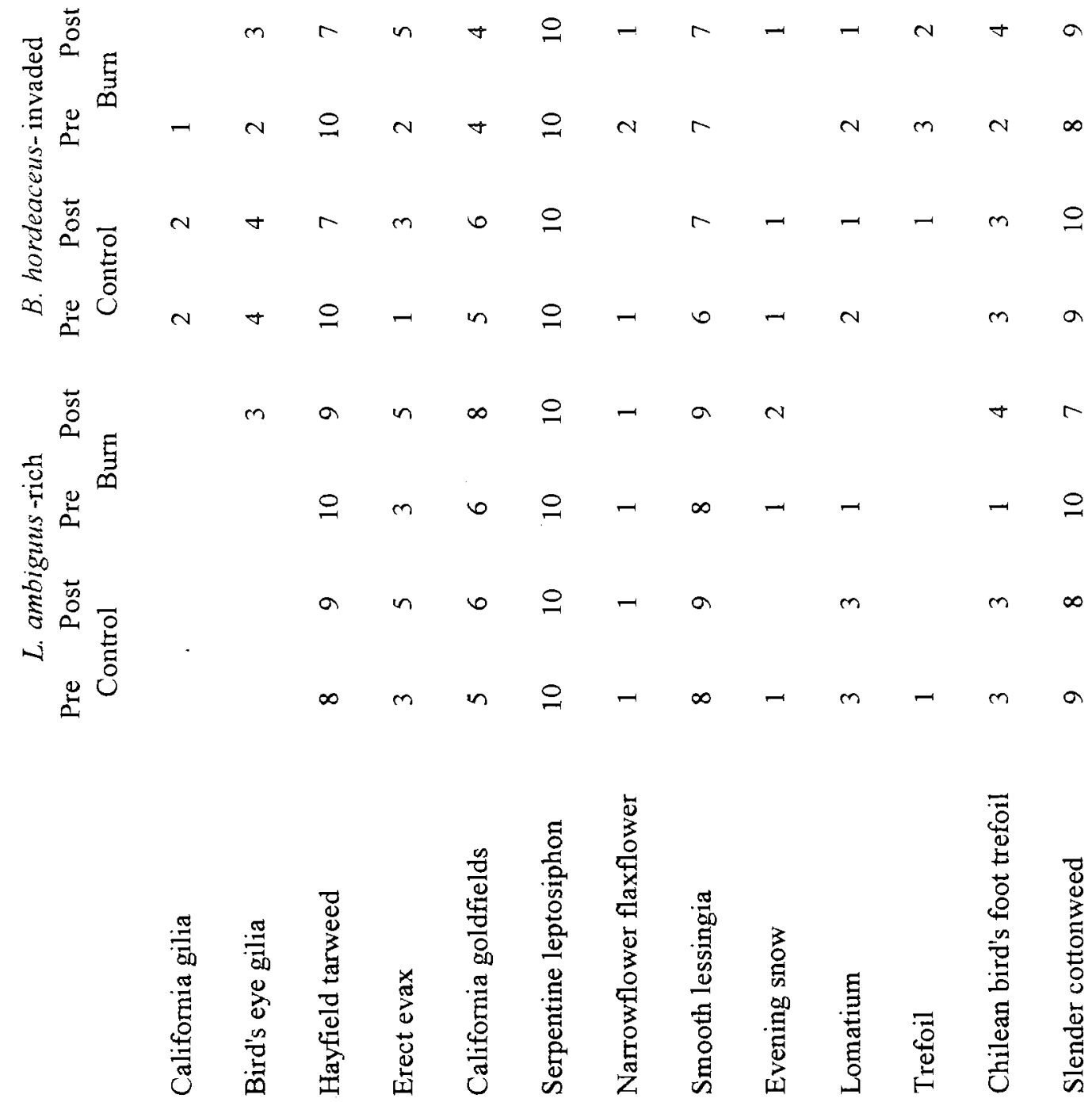

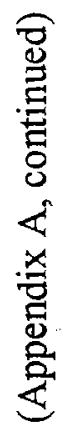

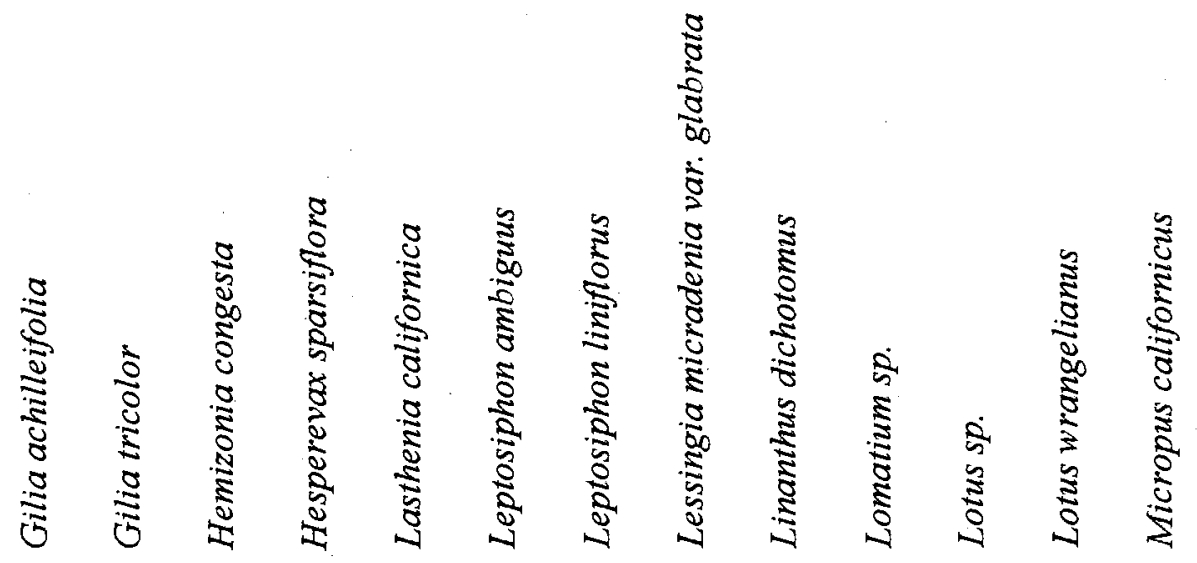



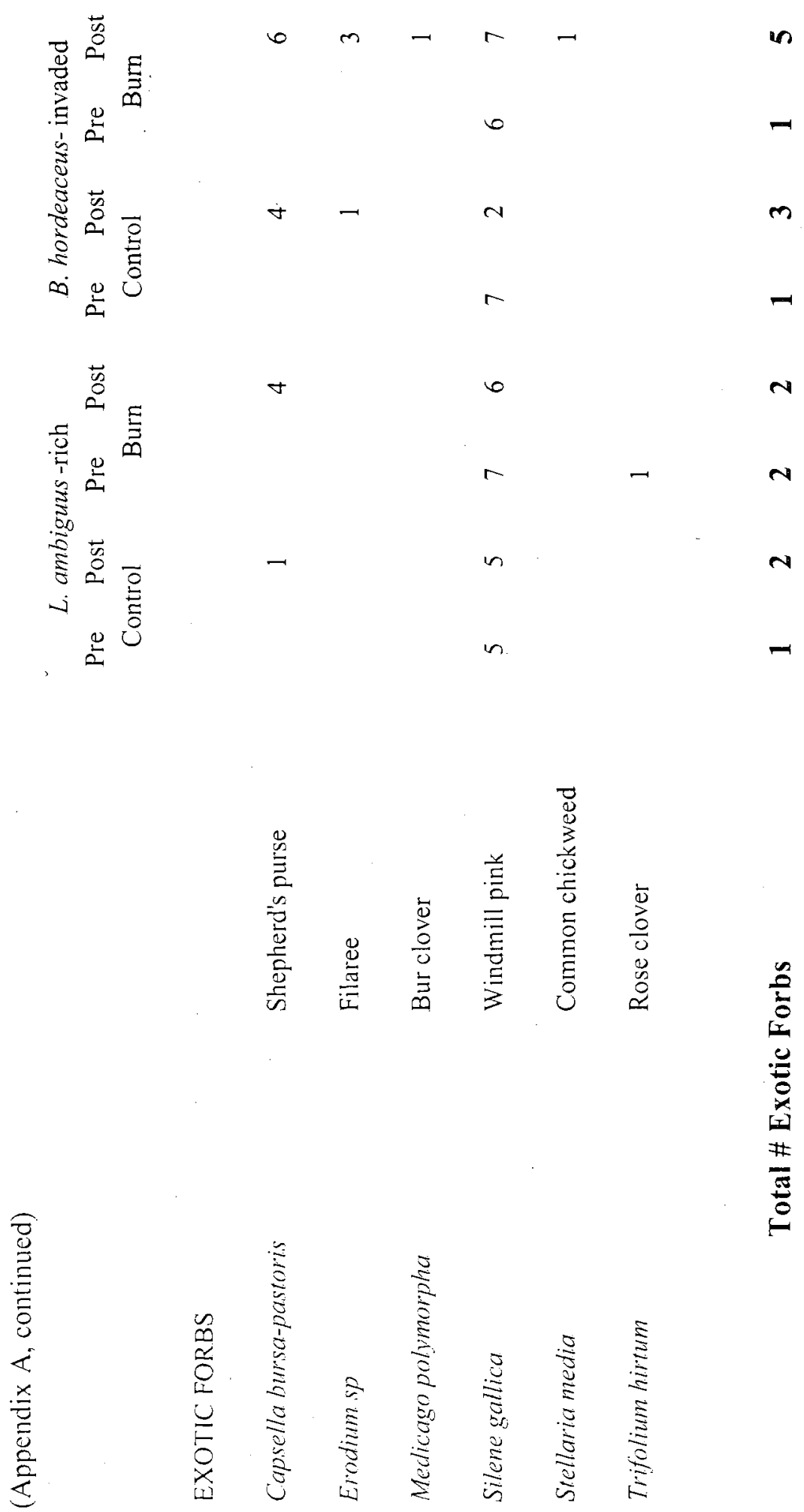

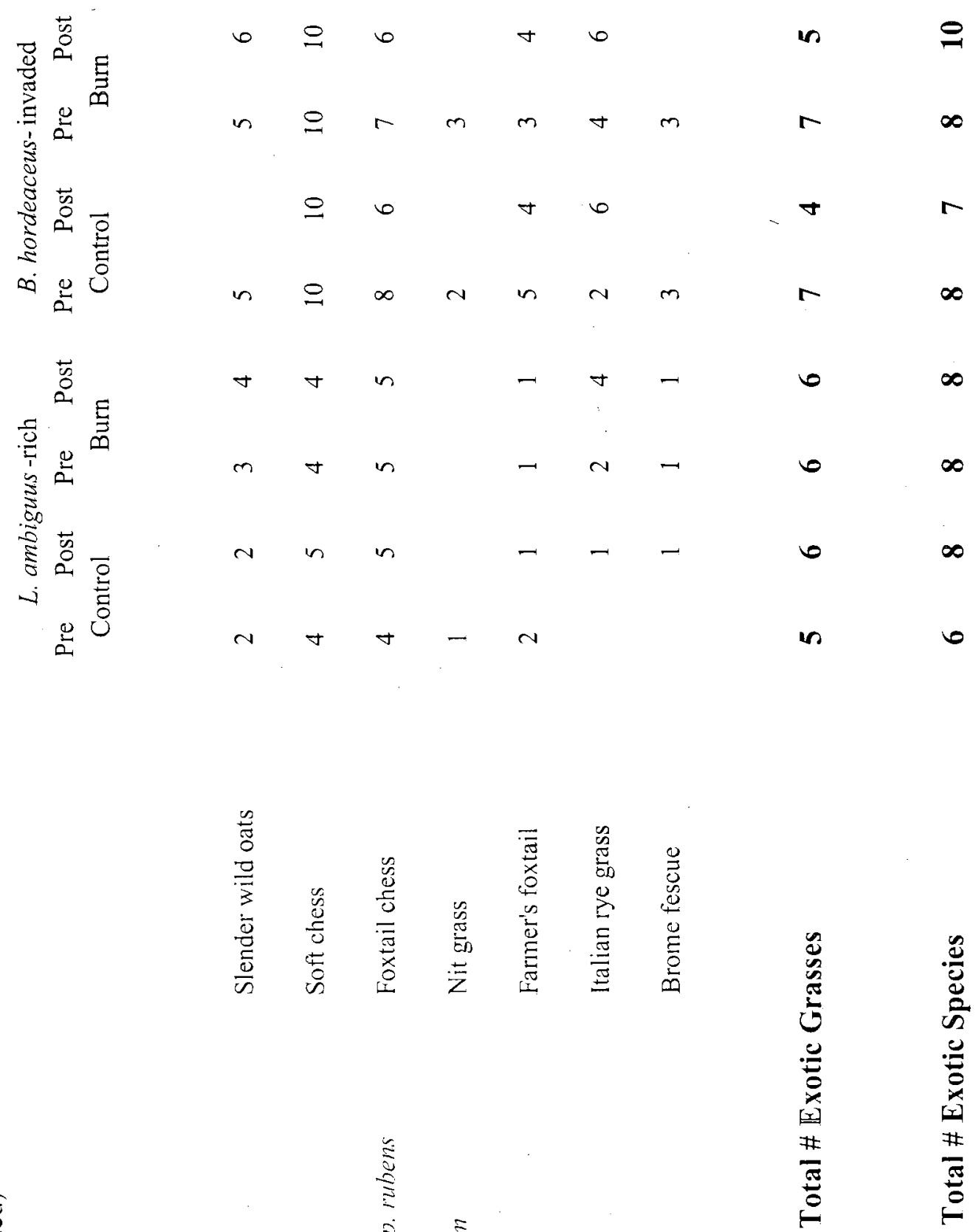

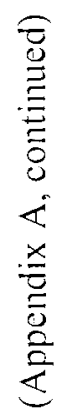

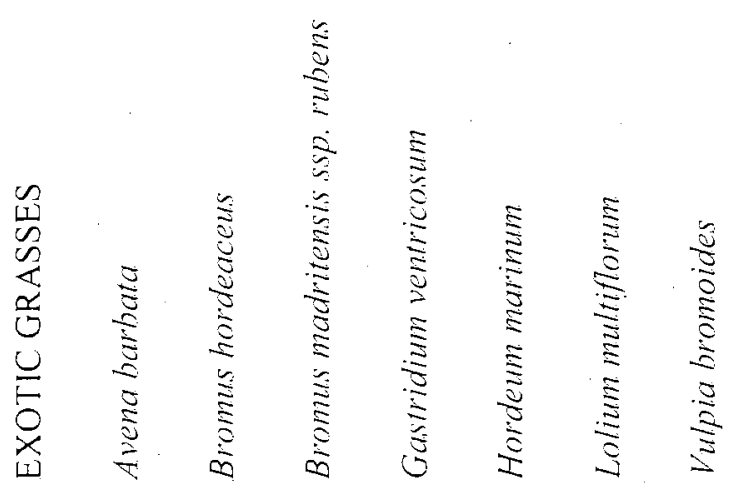

